\title{
Beyond the Ligand: Extracellular and Transcellular G Protein-Coupled Receptor Complexes in Physiology and Pharmacology
}

\author{
Henry A. Dunn, Cesare Orlandi, and Kirill A. Martemyanov \\ Department of Neuroscience, The Scripps Research Institute, Jupiter, Florida
}

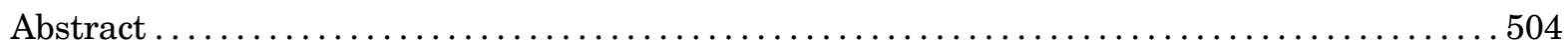

Significance Statement. .................................................. 504

I. The Emerging Extracellular Dimension of G Protein-Coupled Receptor Modulation ........ 504

II. Group III Metabotropic Glutamate Receptors Are Classic Neurotransmitter Receptors

Subject to Transsynaptic Control by Endogenous Allosteric Modulators ............... 505

A. Extracellular Leucine-Rich Repeat and Fibronectin Type III Domain Containing 1 . . .. 506

B. Leucine-Rich Repeat, Immunoglobulin-Like Domain and Transmembrane Domains...... 507

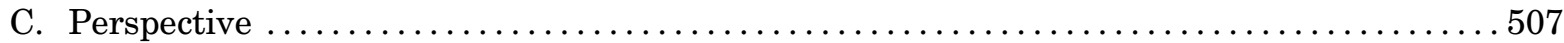

III. Alternative Splicing Defines the Extracellular Interactome of $\gamma$-Aminobutyric Acid

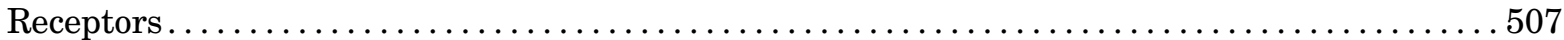

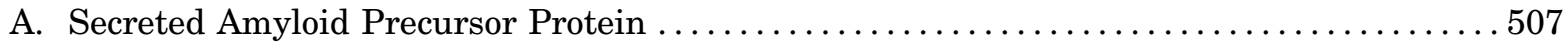

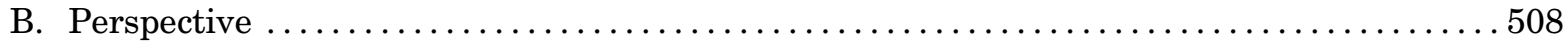

IV. Multimodal Assemblies Involving Adhesion G Protein-Coupled Receptor Subfamily Ls

(Latrophilins) Modulate Axonal Attraction, Repulsion, and Synapse Formation............508

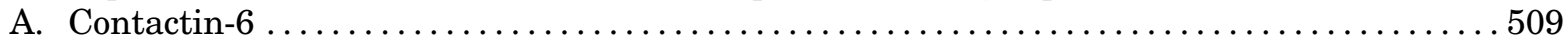

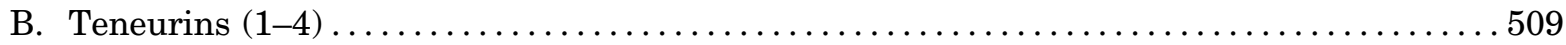

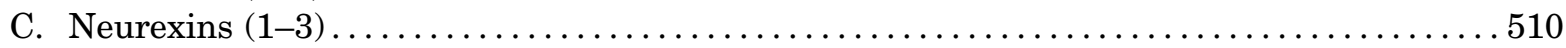

D. Fibronectin Leucine-Rich Transmembranes . . . . . . . . . . . . . . . . . . . . . . . . 510

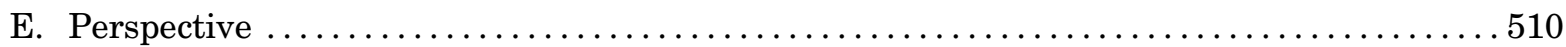

V. Direct Interaction of Adhesion G Protein-Coupled Receptor Subfamily G1/6 (G

Protein-Coupled Receptor 56/126) with Extracellular Matrix Proteins Regulates

Adhesion G Protein-Coupled Receptor Activation Mechanisms...................... 511

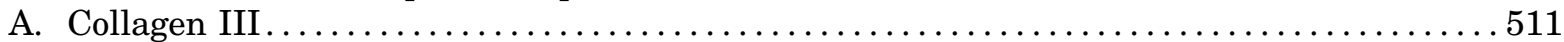

B. Collagen IV .................................................... 511

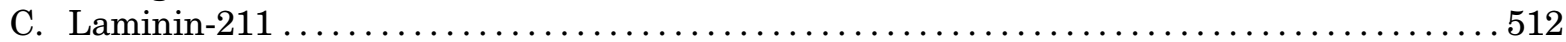

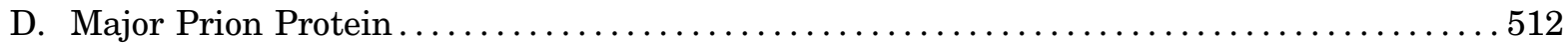

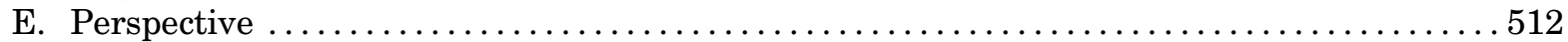

VI. Bidirectional Transsynaptic Coordination of Signaling Involving Complexes Composed of Adhesion G Protein-Coupled Receptor B1-3 (Brain-Specific Angiogenesis Inhibitor 1-3). .... 512

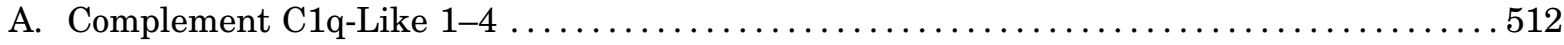

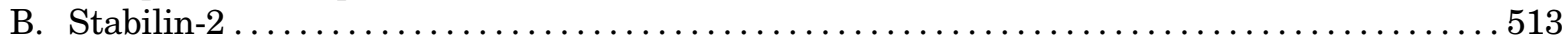

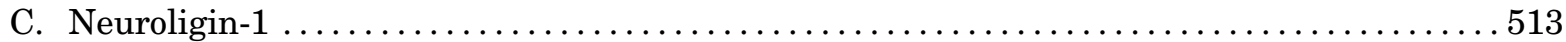

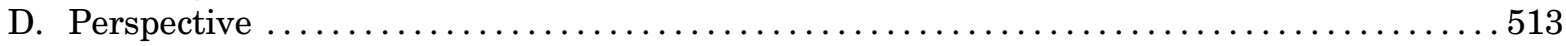

VII. Assembly of Transsynaptic Complexes with Orphan G Protein-Coupled Receptor 158/179

Facilitates Bidirectional Scaffolding of Intracellular Signaling Molecules . . 514

Address correspondence to: Dr. Henry A. Dunn, The Scripps Research Institute, 130 Scripps Way, Jupiter, FL 33458. E-mail: hdunn@ scripps.edu; or Dr. Cesare Orlandi, The Scripps Research Institute, 130 Scripps Way, Jupiter, FL 33458. E-mail: corlandi@scripps.edu; or Dr. Kirill A. Martemyanov, The Scripps Research Institute, 130 Scripps Way, Jupiter, FL 33458. E-mail: kirill@scripps.edu.

Research in the Martemyanov laboratory in the area covered by this review is supported by the National Institutes of Health National Eye Institute [Grant R01 EY018139] and the National Institutes of Health National Institute of Mental Health [Grant R01 MH105482]. H.A.D. is the recipient of a Canadian Institutes of Health Research Postdoctoral Fellowship.

https://doi.org/10.1124/pr.119.018044. 


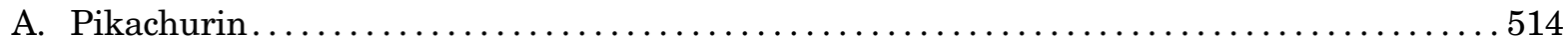

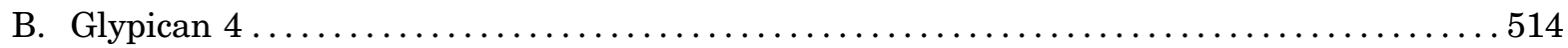

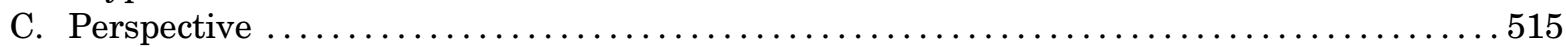

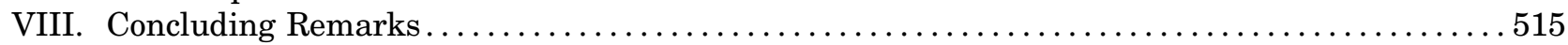

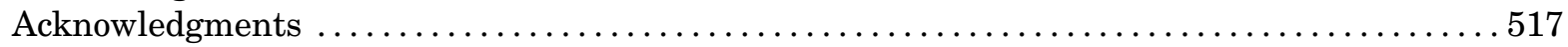

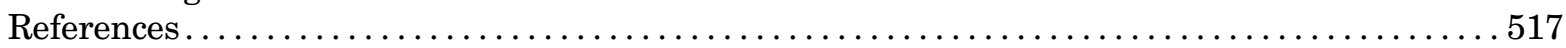

\begin{abstract}
G protein-coupled receptors (GPCRs) remain one of the most successful targets of U.S. Food and Drug Administration-approved drugs. GPCR research has predominantly focused on the characterization of the intracellular interactome's contribution to GPCR function and pharmacology. However, emerging evidence uncovers a new dimension in the biology of GPCRs involving their extracellular and transcellular interactions that critically impact GPCR function and pharmacology. The seminal examples include a variety of adhesion GPCRs, such as ADGRLs/latrophilins, ADGRBs/brain angiogenesis inhibitors, ADGRG1/GPR56, ADGRG6/GPR126, ADGRE5/CD97, and ADGRC3/CELSR3. However, recent advances have indicated that class C GPCRs that contain large extracellular domains, including group III metabotropic glutamate receptors (mGluR4, mGluR6, mGluR7, mGluR8), $\gamma$-aminobutyric acid receptors, and orphans GPR158 and GPR179, can also participate in this form of transcellular regulation. In this review, we will focus on a variety of identified extracellular and transcellular GPCR-interacting partners, including teneurins, neurexins, integrins, fibronectin leucine-rich transmembranes, contactin-6, neuroligin, laminins, collagens, major prion protein, amyloid precursor protein, complement C1q-likes, stabilin-2,
\end{abstract}

pikachurin, dystroglycan, complement decay-accelerating factor CD55, cluster of differentiation CD36 and CD90, extracellular leucine-rich repeat and fibronectin type III domain containing 1 , and leucine-rich repeat, immunoglobulin-like domain and transmembrane domains. We provide an account on the diversity of extracellular and transcellular GPCR complexes and their contribution to key cellular and physiologic processes, including cell migration, axon guidance, cellular and synaptic adhesion, and synaptogenesis. Furthermore, we discuss models and mechanisms by which extracellular GPCR assemblies may regulate communication at cellular junctions.

Significance Statement-G protein-coupled receptors (GPCRs) continue to be the prominent focus of pharmacological intervention for a variety of human pathologies. Although the majority of GPCR research has focused on the intracellular interactome, recent advancements have identified an extracellular dimension of GPCR modulation that alters accepted pharmacological principles of GPCRs. Herein, we describe known endogenous allosteric modulators acting on GPCRs both in cis and in trans.

\section{The Emerging Extracellular Dimension of G Protein-Coupled Receptor Modulation}

G protein-coupled receptors (GPCRs) have long been one of the most targeted family proteins for development of therapeutics. Approximately 35\% of U.S. Food and Drug Administration-approved drugs target GPCRs themselves as well as their associated signaling pathways and interacting partners (Thompson et al., 2005, 2008; Hauser et al., 2017, 2018; Sriram and Insel, 2018). The central dogma of GPCR function posits that signaling is initiated by extracellular ligand binding, followed by a change in conformational state and the recruitment of intracellular heterotrimeric $\mathrm{G}$ proteins, $\beta$-arrestins, and a multitude of other signaling and trafficking machineries (Pavlos and Friedman, 2017; Eichel and von Zastrow, 2018; Hilger et al., 2018). GPCR research has predominantly focused on the functional characterization of this intracellular GPCR interactome and its contribution to GPCR signaling and pharmacology (Ritter and Hall, 2009; Magalhaes et al., 2012; Dunn and Ferguson, 2015). However, GPCRs are increasingly found in complex with extracellular binding partners (Knapp and Wolfrum, 2016). One such example involves receptor activity-modifying proteins, which interact with both the transmembrane and extracellular domains of various GPCRs in cis to modulate signaling and trafficking processes by well established mechanisms (Hay and Pioszak, 2016; Hay et al., 2016; Klein et al., 2016). Intriguingly, recent studies have begun to identify additional GPCR interactions with secreted extracellular proteins, extracellular matrix (ECM) components, and adhesion molecules or multimeric complexes across cellular junctions, or transcellularly. Such interactions

ABBREVIATIONS: ADGRB, adhesion G protein-coupled receptor subfamily B; ADGRC, adhesion G protein-coupled receptor subfamily C; ADGRE, adhesion G protein-coupled receptor subfamily E; ADGRG, adhesion G protein-coupled receptor subfamily G1; ADGRL, adhesion G protein-coupled receptor subfamily L; APP, amyloid precursor protein; DGC, dystrophin-associated glycoprotein complex; ECM, extracellular matrix; EGF, epidermal growth factor; ExD, extension domain; FLRT, fibronectin leucine-rich transmembrane; FN3, fibronectin type III; $\mathrm{GABA}_{\mathrm{B}} \mathrm{R}, \gamma$-aminobutyric acid receptor; GAIN, GPCR autoproteolysis-inducing; GPC, glypican; GPCR, G protein-coupled receptor; GPI, glycosylphosphatidylinositol; HEK293, human embryonic kidney 293; HS, heparan sulfate; HSPG, heparan sulfate proteoglycan; LAR, leukocyte antigen-related tyrosine phosphatase; LRR, leucine-rich repeat; mGluR, metabotropic glutamate receptor; PLL, pentraxin/laminin/ neurexin/sex-hormone-binding-globulin-like; PrP, major prion protein; RGS, regulator of G protein signaling; sAPP, secreted amyloid precursor protein; SD, sushi domain; shRNA, short hairpin RNA. 
have documented critical functional consequences on both higher-order physiologic processes and specific GPCR properties, particularly within the brain. This emerging extracellular and transcellular dimension of GPCR function represents an enormous void in our understanding of GPCR biology that is unaccounted for in the traditional outlook on GPCR biology.

Some of these extracellular and transcellular interactions are shown to be integral for dictating the expression and targeting of GPCRs to discrete membrane compartments (Tomioka et al., 2014; Cao et al., 2015). The emerging picture suggests that these interactions contribute to a variety of molecular and physiologic processes beyond simply providing structural scaffolding across junctions and synapses. For example, the extracellular interactions of GPCRs are involved in the migration of neuronal progenitor cells (Luo et al., 2011, 2014) and control both axonal attraction and repulsion (Jackson et al., 2015, 2016; Vysokov et al., 2018). Furthermore, transcellular interactions with GPCRs are often sufficient to induce formation of cell junctions and synaptogenesis (Hamann et al., 1996; Silva et al., 2011; Boucard et al., 2012, 2014), processes that were previously attributed almost exclusively to cell adhesion molecules. In addition, transsynaptic GPCR complexes can induce both presynaptic differentiation and the development of dendritic spines (O'Sullivan et al., 2012; Boucard et al., 2014; Sigoillot et al., 2015; Condomitti et al., 2018; Tu et al., 2018), indicative of a novel bidirectional cell-to-cell communication mechanism.

Perhaps most importantly, these interactions appear capable of directly regulating GPCR activity by both inducing or inhibiting $\mathrm{G}$ protein coupling and subsequent second messenger signaling (Silva et al., 2011; Hamoud et al., 2014; Luo et al., 2014; Paavola et al., 2014; Petersen et al., 2015; Küffer et al., 2016; Dunn et al., 2018; Li et al., 2018). Mechanistically, it appears that extracellular interactions allosterically modulate efficacies and potencies to endogenous orthosteric ligands (Dunn et al., 2018), thereby illuminating an endogenous mechanism that has been proven highly druggable in a variety of contexts. Finally, recent examples of extracellular regulation of orphan GPCRs have proven integral to their unique biology, and therefore may aid in deorphanization efforts and subsequent characterization of orphan GPCR pharmacology.

Although the majority of GPCRs are expressed in the brain (Vassilatis et al., 2003), which serves as the source of most known examples of transcellular GPCR complexes and the predominant focus of this review, the first example was provided by the interaction between glycosylphosphatidylinositol (GPI)-anchored complement decay-accelerating factor (CD55) and adhesion GPCR subfamily E ADGRE5/CD97, which facilitates adhesion in immune cells (Hamann et al., 1996). The ADGRE5 extracellular interactome was further expanded to include integrin $\alpha_{5} \beta_{1}$ and CD90, which appear to contribute to endothelial targeting of leukocytes and inflammatory cells (Wang et al., 2005; Wandel et al., 2012). Foreseeably, this concept can likely be further extended to other peripheral tissues and their respective cellular junctions; however, the majority of examples have been described in the central nervous system. Nevertheless, the growing list of extracellular and transcellular interactions of GPCRs may represent a general organizational and functional principle of this important protein family expressed within all tissues. Exploring this emerging dimension in traditional GPCR drug design can likely provide novel therapeutic strategies for a variety of neurologic, immunologic, and metabolic conditions. The focus of this review is to provide a systematic account of the functional extracellular and transcellular/transsynaptic interactome of GPCRs, including cell-surface and secreted proteins, matrix proteins, and cellular- and synaptic adhesion molecules (Fig. 1), while detailing the demonstrated implications of these interactions for GPCR signaling, pharmacology, and physiology.

\section{Group III Metabotropic Glutamate Receptors Are Classic Neurotransmitter Receptors Subject to Transsynaptic Control by Endogenous Allosteric Modulators}

Group III metabotropic glutamate receptors (mGluR4, mGluR6, mGluR7, mGluR8) prototypically provide homeostatic regulation of excitatory neurotransmission by acting as glutamatergic autoreceptors on the presynaptic terminals of neurons, thereby providing a negative feedback loop that limits glutamate release (Niswender and Conn, 2010; Nicoletti et al., 2011; Niciu et al., 2012). However, these receptors can also act postsynaptically. In the retina, for example, mGluR6 is exclusively localized at the dendritic tips of ON-bipolar neurons where its actions are indispensable for the transmission of photoreceptor-generated signal (Gerber, 2003). mGluR4, mGluR7, and mGluR8 are expressed widely throughout the brain where they have been collectively implicated in a variety of higher-order neurophysiological processes, including synaptic plasticity, learning, and memory (Niswender and Conn, 2010; Nicoletti et al., 2011). Furthermore, this group of receptors has been implicated in a myriad of neurologic and neuropsychiatric disorders, including epilepsy, anxiety, and depression (Lavreysen and Dautzenberg, 2008; Niswender and Conn, 2010; Nicoletti et al., 2011; Amalric et al., 2013; Gregory et al., 2013; Becker et al., 2014; Palazzo et al., 2016). Group III mGluRs belong to the class C family of GPCRs characterized in part by their large extracellular domains. Prototypically, these domains are involved in detecting extracellular glutamate and translating this event into activation of $\mathrm{G}$ proteins of the $\mathrm{G} \alpha_{\mathrm{i} / \mathrm{o}}$ subfamily (Niswender and Conn, 2010). However, 

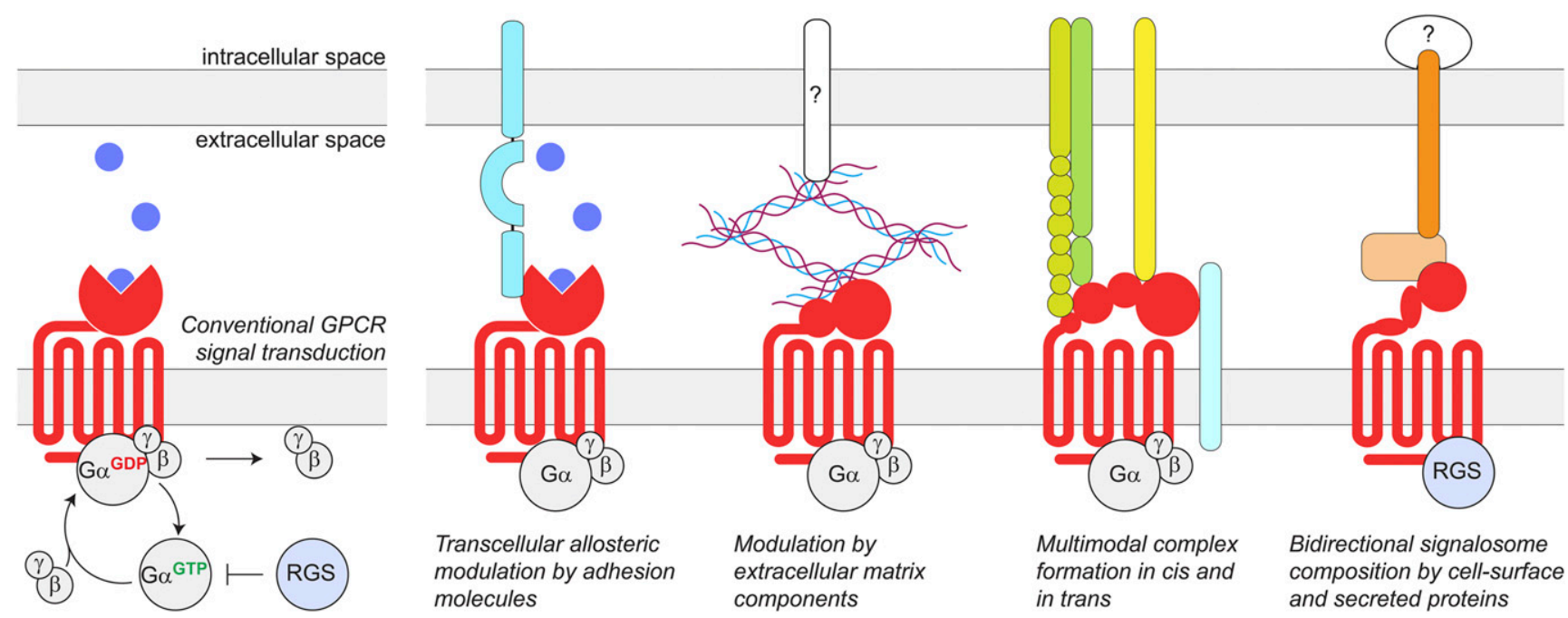

Fig. 1. Conventional GPCR signal transduction and the emergence of transcellular GPCR complexes. Traditionally, the extracellular surface of GPCRs is viewed as a site for interaction with ligands initiating GPCR-mediated intracellular signaling. This involves a conformational change and subsequent activation of the heterotrimeric G protein, thereby inducing the exchange of GDP for GTP on the G $\alpha$-subunit and the dissociation of G $\alpha$ from $\mathrm{G} \beta \gamma$-subunits. Subsequent $\mathrm{G} \alpha$-mediated hydrolysis of GTP to GDP enables the reassociation with $\mathrm{G} \beta \gamma$ to terminate G protein signaling, a process catalyzed by RGS proteins. However, it is now emerging that GPCRs also form a variety of extracellular interactions generalized in the scheme. These complexes are highly diversified and can create junction- or synapse-specific environments to endow GPCR function with specific properties.

recent findings indicate that group III mGluRs also engage in transcellular interactions capable of modulating their functional properties and playing essential roles in synapse formation (Tomioka et al., 2014; Cao et al., 2015; Dunn et al., 2018). These interactions involve at least two proteins: extracellular leucine-rich repeat and fibronectin type III domain containing 1 (ELFN1) and leucine-rich repeat, immunoglobulin-like domain and transmembrane domains (LRITs).

\section{A. Extracellular Leucine-Rich Repeat and Fibronectin Type III Domain Containing 1}

ELFN1 is a single-pass transmembrane protein hosting multiple leucine-rich repeats (LRRs) and a fibronectin type III (FN3) domain in the extracellular domain. ELFN1 was described to play a role in regulating neurotransmitter release probability (Sylwestrak and Ghosh, 2012). However, the mechanism of this action was uncertain. Subsequently, ELFN1 was found to form transsynaptic complexes with mGluR7, promoting its synaptic recruitment in hippocampal neurons in a subtype-selective manner (Tomioka et al., 2014). Concurrently, ELFN1 was also found to interact with retinal-specific mGluR6 (Cao et al., 2015) and was then established as a universal binding partner of all group III mGluRs (Dunn et al., 2018). In the retina, knockout of ELFN1 results in the downregulation of mGluR6 expression and a loss of its accumulation specifically at the synapses formed by rod but not cone photoreceptors. As a result, ELFN1-deficient mice feature selective deficits in rod-mediated dim vision and not cone-mediated daylight vision (Cao et al., 2015). Together, observations in both hippocampal and retinal neurons provide an example of transsynaptic GPCR complexes modulating and perhaps defining specific neural circuitry while suggesting that mGluR-ELFN1 transcomplexes play an important role in selective synaptic wiring and function.

Importantly, interaction with ELFN1 also bears functional implications on mGluR signaling. The phenomenon of allosteric modulation has been well established for group III mGluRs, aided in large part by their extensive pharmacological characterization and the availability of pharmacological tools including selective allosteric modulators (Lindsley et al., 2016). These well established principles of group III mGluR pharmacology have prompted studies for the determination of the direct functional outcome of ELFN1 transassociation. Using a transcellular GPCR signaling assay (Dunn et al., 2018), it was reported that ELFN1 supplied in trans promoted constitutive activity of two representative group III members, mGluR6 and mGluR4, but not group II mGluR2, which does not bind (Dunn et al., 2018). The ability of ELFN1 to promote group III mGluR constitutive activity was further supported by the induction of mGluR7-mediated G protein-gated inwardly rectifying $\mathrm{K}^{+}$channel activation upon administration of the ELFN1 ectodomain (Stachniak et al., 2019). This suggests that ELFN1 binding influences conformational transitions in group III mGluRs related to their activation. Indeed, transcellular association with ELFN1 influences both the efficacy and potency of class III mGluRs for orthosteric agonists (Dunn et al., 2018). As a result, ELFN1 binding negatively modulated $\mathrm{G} \alpha_{\mathrm{i} / \mathrm{o}}$ coupling and signaling to downstream second messenger pathways (Dunn et al., 2018). These transcellular effects were not a consequence of altered surface targeting or desensitization of receptors, suggesting that ELFN1 acts as an endogenous allosteric modulator of group III mGluRs (Dunn et al., 2018). These observations 
are further supported in vivo by the enhanced synaptic suppression by orthosteric group III mGluR agonists in ELFN1 knockout (Stachniak et al., 2019). Thus, it appears that mGluR-ELFN1 transcomplexes not only provide integral transsynaptic structure for stabilizing group III mGluR expression at specific synaptic locations, but they also critically and selectively alter mGluR pharmacology and thus endow the synapse with specific functional characteristics.

\section{B. Leucine-Rich Repeat, Immunoglobulin-Like Domain and Transmembrane Domains}

LRIT1-LRIT3 are single-pass transmembrane adhesion molecule-like proteins characterized by multiple LRRs, an immunoglobulin-like C2-type domain, and an FN3 domain in the extracellular space. LRIT1 and LRIT2 were both recently identified as binding partners of retina-specific mGluR6 (Sarria et al., 2018; Ueno et al., 2018). Unlike the situation with the ELFN1 knockout, loss of LRIT1 does not cause significant downregulation or mistargeting of mGluR6 at the synapse (Cao et al., 2015; Sarria et al., 2018; Ueno et al., 2018). However, knockout of LRIT1 produces marked effects on synaptic transmission that are postulated to originate from changes in mGluR6 function (Sarria et al., 2018; Ueno et al., 2018). Curiously, LRIT3, a close homolog of LRIT1 and LRIT2, also plays an essential role in mGluR6-mediated synaptic transmission (Neuillé et al., 2014, 2015, 2017), but it has not yet been reported to form complexes with the receptor. Although the functional role of mGluR6 interactions with LRIT1-LRIT3 and the mechanisms involved in mGluR6 regulation remain to be determined, it is plausible that LRITs may act in a similar pharmacological capacity as ELFN1.

\section{Perspective}

The emerging concept from the studies on group III mGluRs is that these receptors use their large extracellular domains not only for binding of the neurotransmitter glutamate but also for association with other extracellular proteins. These interactions are crucial for the formation of synapses and endow them with specific properties via the stabilization of various conformational states on the continuum of GPCR activation and inactivation. In the case of group III mGluR autoreceptors, transsynaptic interactions with postsynaptic ELFN1 tunes presynaptic release probability to regulate synaptic transmission properties, whereas transsynaptic interactions with LRITs may provide means for further fine-tuning receptor-mediated contributions to signal transmission. Considering that many class C GPCRs feature extracellular domains of similar organization to group III mGluRs, it is likely that these concepts can be expanded to other members of the family. In particular, transsynaptic allosteric modulation of GPCR signaling is an emerging concept that could be applicable to many GPCRs for which pharmacological modulators are found.

\section{Alternative Splicing Defines the Extracellular Interactome of $\boldsymbol{\gamma}$-Aminobutyric Acid Receptors}

Metabotropic $\gamma$-aminobutyric acid receptors $\left(\mathrm{GABA}_{\mathrm{B}} \mathrm{Rs}\right)$ are neuronal GPCRs localized both at pre- and postsynaptic terminals. With GABA being the main inhibitory neurotransmitter in the central nervous system, $\mathrm{GABA}_{\mathrm{B}} \mathrm{Rs}$ mediate the slow GABA neuromodulatory effects by activating $G$ proteins of the $\mathrm{G}_{\mathrm{i} / \mathrm{o}}$ family (Pinard et al., 2010). By regulating a variety of intracellular effectors such as $G$ protein-gated inwardly rectifying $\mathrm{K}^{+}$channels, voltage-gated $\mathrm{Ca}^{2+}$ channels, and adenylate cyclases, $\mathrm{GABA}_{\mathrm{B}} \mathrm{Rs}$ control important aspects of cognition, memory, mood, nociception, and motor coordination (Bowery, 2006; Padgett and Slesinger, 2010; Heaney and Kinney, 2016).

The two family members $\left(\mathrm{GABA}_{\mathrm{B}} \mathrm{R} 1\right.$ and $\left.\mathrm{GABA}_{\mathrm{B}} \mathrm{R} 2\right)$ of this class $\mathrm{C}$ GPCR family represent a prominent example of GPCR heterodimerization, as both subunits are constitutively required to create a fully functional complex (Jones et al., 1998; Kaupmann et al., 1998; White et al., 1998). Mechanistically, $\mathrm{GABA}_{\mathrm{B}} 1 \mathrm{R}$ contains the agonist binding site, whereas counterpart $\mathrm{GABA}_{\mathrm{B}} 2 \mathrm{R}$ is required to target $\mathrm{GABA}_{\mathrm{B}} 1 \mathrm{R}$ to the plasma membrane and to activate G proteins (Jones et al., 1998; Kaupmann et al., 1998; White et al., 1998). As prototypical class $\mathrm{C}$ GPCRs, GABA ${ }_{B} R$ ectodomains exhibit the threedimensional Venus flytrap structure that serves as the orthosteric ligand-binding site (Geng et al., 2012). Interestingly, the subunit $\mathrm{GABA}_{\mathrm{B}} \mathrm{R} 1 \mathrm{a}$, generated by alternative splicing, contains an additional $\mathrm{N}$-terminal extension that includes a pair of sushi domains (SDs) (Hawrot et al., 1998) that were proposed to participate in extracellular protein-protein interactions (Marshall et al., 1999; Blein et al., 2004) and are integral for presynaptic targeting and surface stability (Vigot et al., 2006; Tiao et al., 2008; Biermann et al., 2010; Hannan et al., 2012). Recent studies revealed that a specific binding partner of $\mathrm{GABA}_{\mathrm{B}} \mathrm{R} 1 \mathrm{SDs}$ is the secreted amyloid precursor protein (sAPP) (Schwenk et al., 2016; Rice et al., 2019).

\section{A. Secreted Amyloid Precursor Protein}

Amyloid precursor protein (APP) is a single-pass transmembrane protein that can be cleaved by multiple members of the secretase family to release its extracellular domain (De Strooper et al., 2010). sAPP has been implicated in the regulation of a range of protective neurophysiological functions both in the peripheral and central nervous system (Müller et al., 2017), including inhibition of neuronal apoptosis (Gralle et al., 2009), stimulation of adult neurogenesis (Caillé et al., 2004), and suppression of synaptic activity 
(Furukawa et al., 1996), thereby serving a crucial role in synaptic plasticity, learning, and memory (Ishida et al., 1997; Meziane et al., 1998; Taylor et al., 2008; Xiong et al., 2017). Notably, abnormal cleavage of APP leads to accumulation of the amyloid- $\beta$ peptide that has been implicated in the development of Alzheimer disease (Glenner and Wong, 1984). The APP ectodomain consists of two extracellular functional domains, named $\mathrm{E} 1$ and E2, divided by a linker region. The $\mathrm{N}$-terminal E1 contains a growth factor-like domain and a copper binding domain, whereas the linker region is further subdivided in an acidic domain and an extension domain $(\mathrm{ExD})$.

Proteomic analysis revealed that sAPP is part of the extracellular interactome of $\mathrm{GABA}_{\mathrm{B}} \mathrm{R}$ (Schwenk et al., 2016). More recently, it was established that the ExD of APP contains the minimal binding sequence to interact specifically with SD1 of GABA ${ }_{B} R 1 a$, suggesting alternative splicing of $\mathrm{GABA}_{\mathrm{B}} \mathrm{Rs}_{\mathrm{s}}$ as an integral component of dictating and diversifying their extracellular interactomes (Dinamarca et al., 2019; Rice et al., 2019). Functionally, treatment of sAPP or a synthesized 17-amino-acid peptide derived from the ExD sequence was demonstrated to decrease presynaptic strength and vesicle release probability dependent on GABA $_{B} R$ activity (Rice et al., 2019), which suggests that sAPP interactions may act to initiate or modulate $\mathrm{GABA}_{B} R$ signaling. However, another recent study was unable to detect changes in $\mathrm{GABA}_{\mathrm{B}} \mathrm{R}$-mediated $\mathrm{G}$ protein activation in response to APP/sAPP (Dinamarca et al., 2019). Nevertheless, $G_{A B A_{B}} R 1 a$ axonal localization was shown to be dependent on APP expression (Dinamarca et al., 2019), providing a possible mechanism for the essentiality of alternatively spliced $\mathrm{GABA}_{\mathrm{B}} \mathrm{R} 1 \mathrm{a}$ SDs in synaptic targeting and membrane stability (Vigot et al., 2006; Tiao et al., 2008; Biermann et al., 2010; Hannan et al., 2012).

\section{B. Perspective}

$\mathrm{GABA}_{\mathrm{B}} \mathrm{Rs}$ are among the most abundant GPCRs expressed in the central nervous system. Unlike mGluRs that are encoded by eight separate genes to generate a range of signaling responses, only two genes encode the two obligatory subunits required to generate a single functional $\mathrm{GABA}_{\mathrm{B}} \mathrm{R}$ heterodimer. Nonetheless, a variety of physiologic effects produced by GABA activation of its metabotropic receptors have been reported in the literature (Pinard et al., 2010). To attain a variety of functional outcomes, alternative splicing events in the extracellular region appear to diversify $\mathrm{GABA}_{\mathrm{B}} \mathrm{R}$ isoforms to bear distinguishing extracellular proteinprotein interaction domains, thereby providing unique extracellular interactomes. For example, $\mathrm{GABA}_{\mathrm{B}} \mathrm{R} 1 \mathrm{a}$ could be appropriately localized and/or allosterically controlled by APP, whereas other isoforms lacking the SD would not be subject to this modulation, thereby providing differential tuning of $\mathrm{GABA}_{\mathrm{B}} \mathrm{R}$ signaling.
This extracellular regulation is likely further diversified by additional validated SD interactions that remain to be characterized (Dinamarca et al., 2019). This increased complexity would appear necessary to achieve versatile control over inhibitory neurotransmission.

\section{Multimodal Assemblies Involving Adhesion G Protein-Coupled Receptor Subfamily Ls (Latrophilins) Modulate Axonal Attraction, Repulsion, and Synapse Formation}

Adhesion GPCR subfamily Ls (ADGRLs; alternatively known as latrophilins) were first discovered as high-affinity substrates of $\alpha$-latrotoxin, the active ingredient in black widow spider venom (Davletov et al., 1996; Krasnoperov et al., 1996). This potent neurotoxin causes synaptic excitotoxicity via the induction of glutamate exocytosis partially attributed to its actions on ADGRLs (Krasnoperov et al., 1996), suggestive of ADGRLs' importance for synaptic function. Indeed, subsequent studies demonstrated roles of ADGRLs in neuronal development and establishment of synaptic connectivity and implicated them in complex neuropsychiatric disorders (Arcos-Burgos et al., 2010; Ribasés et al., 2011; Labbe et al., 2012; Bruxel et al., 2015; Acosta et al., 2016; Martinez et al., 2016; Anderson et al., 2017). Furthermore, ADGRLs have been implicated as mechanosensors in chordotonal organs (Scholz et al., 2017) and are expressed in multiple peripheral tissues, including the heart, liver, and kidney, suggestive of a broader role independent of their neuronal functions (Boucard et al., 2014). ADGRLs, like ADGRE5, ADGRB1-3, ADGRG1/6, and ADGRC3 discussed in this review, belong to a larger class of adhesion GPCRs characterized by their large extracellular ectodomains. Within the ectodomain, ADGRLs prototypically contain a lectin domain, an olfactomedin domain, and a GPCR autoproteolysis-inducing (GAIN) domain necessary for the autoproteolytic cleavage and exposure of the "Stachel" peptide tethered agonist, which plays a key role in adhesion GPCR activation (Araç et al., 2012, 2016; Liebscher et al., 2014; Stoveken et al., 2015; Kishore and Hall, 2016; Nieberler et al., 2016; Folts et al., 2019). Nevertheless, alternative activation mechanisms of adhesion GPCRs independent of autoproteolysis or Stachel peptide tethered agonists have been described (Salzman et al., 2017; Scholz et al., 2017) and extensive literature on adhesion GPCRs and their activation mechanisms was recently documented (Araç et al., 2012, 2016; Liebscher et al., 2014; Stoveken et al., 2015; Kishore and Hall, 2016; Nieberler et al., 2016; Folts et al., 2019).

The extracellular domains of ADGRLs have been demonstrated to associate with a remarkable diversity of synaptic adhesion molecules both in cis and in trans, as accounted below. Although ADGRLs are generally known for their contributions to extracellular structure, 
recent studies have conclusively demonstrated their ability to couple to canonical $G$ protein pathways and thus serve as bona fide GPCRs (Li et al., 2018; Nazarko et al., 2018). Mechanistically, the multitude of extracellular and transcellular interactions of ADGRLs are capable of stabilizing various states of receptor activation/inactivation to coordinate cellular processes from neurite outgrowth, axonal attraction, and synaptogenesis to axonal repulsion and apoptosis. The following are the most prominent examples of such associations.

\section{A. Contactin-6}

Contactin-6 is a synaptic adhesion molecule involved in the regulation of axon guidance cues (Stoeckli, 2010). This protein belongs to the immunoglobulin superfamily and contains a large extracellular domain composed of six immunoglobulin-like domains and four FN3 domains tethered to the membrane by a GPI anchor. Contactin- 6 has been demonstrated to form a cis-complex with ADGRL1 (Zuko et al., 2016). ADGRL1 expression in cultured neurons inhibits neurite outgrowth and increases apoptosis, whereas coexpression of contactin- 6 reverses these processes (Zuko et al., 2016). Accordingly, cultured neurons from contactin- 6 knockout mice show increased apoptosis, which is rescued by the knockdown of ADGRL1 (Zuko et al., 2016). Therefore, it appears the extracellular regulation of ADGRL1 via cis interactions with contactin-6 plays an important role in initiating or biasing signaling events necessary for maintaining neurite outgrowth and preventing apoptosis.

\section{B. Teneurins (1-4)}

Teneurins are large, transmembrane synaptic adhesion molecules with functional implications in neurite outgrowth, cell adhesion, and synapse formation (Kenzelmann et al., 2007; Young and Leamey, 2009). The extracellular portion of teneurins is characterized by multiple YD repeats, NCL-1, HT2A and Lin-41 (NHL) repeats, and epidermal growth factor (EGF)-like domains. The association of teneurins with ADGRLs and its selectivity has not yet been assessed systematically; however, studies of individual members point to a common interaction mechanism. It has been demonstrated that the extracellular portion of teneurin-2 utilizes the distal globular region of the carboxyl terminus encompassing the YD and NHL repeats for binding to ADGRLs. Furthermore, studies on teneurin-1 show that both the olfactomedin and lectin extracellular domains of ADGRL3 are required for the formation of these transcomplexes, suggestive of the interaction mechanisms that may underlie interactions between ADGRLs and teneurins in general (O'Sullivan et al., 2014).

Functionally, ADGRL-teneurin interactions appear to be highly synaptogenic. Coculture of ADGRL-expressing and teneurin-2/4-expressing cells leads to their aggregation and the formation of transcellular junctions enriched in ADGRLs and teneurin-2/4 on opposing membranes (Silva et al., 2011; Boucard et al., 2014). Furthermore, in alignment with the transsynaptic nature of their interactions, ADGRL1 and teneurin-2 are localized on opposing synaptic membranes at preand postsynaptic terminals, respectively (Silva et al., 2011; Vysokov et al., 2018). ADGRL1-expressing human embryonic kidney 293 (HEK293) cells can form adhesive contacts with hippocampal neurons upon their coculturing and induce the recruitment of postsynaptic density PSD-95 to the junction (Silva et al., 2011). Conversely, teneurin-2-expressing HEK293 cells attract synapsinpositive axonal varicosities of hippocampal neurons and increase axonal fasciculation (Silva et al., 2011; Vysokov et al., 2018). The importance of ADGRL-teneurin transcomplexes in synaptic development is further reinforced by observations that disrupting this interaction with a selective dominant negative strategy reduces the density of synapses in cultured neurons (Boucard et al., 2014; O'Sullivan et al., 2014). Furthermore, the reduction in synaptic densities in ADGRL3 knockdown is unable to be rescued by reintroduction of ADGRL3 lacking the olfactomedin domain necessary for teneurin binding (O'Sullivan et al., 2014), suggesting that specific ADGRL-teneurin transsynaptic interactions are required for selective synaptic development.

Notably, in addition to interactions involving membrane tethered partners, ADGRLs can also bind and be regulated by the soluble fragments derived from teneurins. For example, the teneurin- 2 ectodomain is proteolytically cleaved during neuronal development, resulting in the release of a portion of soluble ectodomain into the extracellular space (Vysokov et al., 2016, 2018). This process of ectodomain secretion and diffusion in the extracellular space provides a tangible mechanism for the attraction of axons that have yet to form synaptic junctions on dendritic spines. In fact, a gradient of soluble teneurin-2 ectodomain can completely replicate the effect of the full-length protein acting in an ADGRL1-dependent fashion (Vysokov et al., 2018). An analogous mechanism appears to also operate for ADGRC3, which involves association with cleavable glycoprotein dystroglycan to guide axon tract formation in several brain regions (Lindenmaier et al., 2019).

It is hypothesized that secreted ectodomains and membrane tethered interactions may have differential signaling outcomes on the ADGRLs. For example, administration of the soluble ectodomain of teneurin-2, which hosts a toxin-like structural domain that shares sequence motifs with hormone and neuropeptide precursors (Li et al., 2018), induces $\mathrm{Ca}^{2+}$ signaling in presynaptic boutons of hippocampal neurons and neuroblastoma cells expressing ADGRL1 (Silva et al., 2011; Vysokov et al., 2018). Furthermore, this soluble ectodomain induces miniature end-plate potentials in prepared neuromuscular junctions that are abrogated in ADGRL1 knockout mice, thereby indicating the induction of ADGRL1-mediated signaling (Silva et al., 2011; 
Vysokov et al., 2018). Importantly, the transcellular interactions with full-length teneurin-2 have been noted to produce distinct functional effects on ADGRL1, affecting its ability to regulate cAMP accumulation when expressed in HEK293 cells (Li et al., 2018). Therefore, both transmembrane teneurins and soluble ectodomain fragments are capable of modulating ADGRL signaling pathways, perhaps with biased signaling outcomes. Under this model of differential ADGRL signal regulation, the nature of ADGRL-teneurin interactions could bias signaling to serve a dual purpose as both modulators of axonal attraction, growth path, and fasciculation via the release of soluble teneurin ectodomain and subsequent induction of $\mathrm{Ca}^{2+}$ accumulation, and as important mediators of synaptic adhesion with contributions to transsynaptic structural formation and subsequent ADGRL-mediated signaling ultimately leading to a reduction of cAMP.

\section{Neurexins (1-3)}

Neurexins are transmembrane synaptic adhesion molecules characterized by multiple laminin G- and EGF-like domains in their extracellular domains. $\beta$-neurexins are distinguished by their retention of a short $\beta$-neurexin-specific sequence followed by a single laminin G-like domain in their ectodomains (Ushkaryov et al., 1994). Interestingly, $\beta$-neurexins have been demonstrated to form transcomplexes with ADGRLs, and this interaction is altered via differential splicing within the terminal laminin G-like domain (Boucard et al., 2012). This laminin G-like domain is thought to be responsible for the binding of $\beta$-neurexin variants to the extracellular olfactomedin domain of ADGRLs (Boucard et al., 2012). Prototypically, both ADGRLs and neurexins are presynaptic proteins, suggesting that their canonical interactions occur in cis. However, both ADGRLs and neurexins have also been found at postsynaptic sites, supporting the potential relevance of the observed transcellular interactions to the central nervous system (Taniguchi et al., 2007; Anderson et al., 2017). At the functional level, complex formation of ADGRL1 with $\beta$-neurexins facilitates cell-cell adhesion through recruitment of ADGRL and neurexins to transcellular adhesion complexes on opposing membranes (Boucard et al., 2012). Interestingly, the soluble ectodomain of neurexin- $1 \beta$ has been noted to cointernalize with ADGRL1 (Boucard et al., 2012), suggesting its involvement in ADGRL1 activation and subsequent receptor desensitization. However, further studies will be required to determine whether neurexins serve as ADGRL modulators to influence ADGRLmediated signaling or simply provide transcellular structure for facilitating cell adhesion.

\section{Fibronectin Leucine-Rich Transmembranes}

As the name suggests, fibronectin leucine-rich transmembranes FLRT1-FLRT3 are transmembrane adhesion molecules characterized by multiple LRRs and an
FN3 domain in their extracellular domain. Both FLRT2 and FLRT3 have been demonstrated to form transsynaptic complexes with ADGRL1 and ADGRL3 (O'Sullivan et al., 2012; Jackson et al., 2015, 2016; Lu et al., 2015). Unlike teneurins, which require both the olfactomedin and lectin domains of ADGRL for their interactions, binding of FLRTs seems to be mediated only by the lectin domain (O'Sullivan et al., 2012). Similar to teneurins and neurexins, FLRTs also modulate cell-cell interactions via transcellular association with ADGRLs (Jackson et al., 2015, 2016). In addition to ADGRLs, FLRTs can simultaneously interact with uncoordinated-5 (Unc5) and this binding appears to induce a conformational switch that instead inhibits cell adhesion ( $\mathrm{Lu}$ et al., 2015; Jackson et al., 2016). Although the mechanism has not yet been described, this complex formation may provide for altered ADGRL signaling or simply disrupt or facilitate additional interacting partners important for adhesion mechanisms. Nevertheless, FLRTs can provide dual function to either facilitate or inhibit ADGRL-mediated adhesion dependent on their binding to Unc5. This dual function in both adhesion and repulsion is exemplified by ADGRL3FLRT2 transcomplexes. They contribute to cortical neuron repulsion in a manner dependent on an intact FLRT-binding site on ADGRL3 (Jackson et al., 2015). Conversely, administration of soluble FLRT-binding ADGRL1/3 peptides, ADGRL3 short hairpin RNA (shRNA), or FLRT3 shRNA reduces excitatory synapse density in cultured neurons, suggestive of a positive role in adhesion and synaptic development (O'Sullivan et al., 2012; Boucard et al., 2014). Furthermore, FLRT3 shRNA in vivo decreases the strength of afferent inputs and the number of dendritic spines in dentate granule cells in support of its positive role in synaptic development (O'Sullivan et al., 2012). Taken together, ADGRL-FLRT transcomplexes play a critical role in modulating synapse formation and development by opposing mechanisms that involve both facilitation and repulsion of synaptic adhesion depending on the presence of Unc5 in the complex. At this time, it is unclear whether FLRTs have any role in modulating ADGRL-mediated signaling in trans; however, it is foreseeable that ADGRL-FLRT complexes in the presence or absence of Unc5 could differentially modify ADGRL signaling to promote repulsion or adhesion mechanisms, respectively.

\section{E. Perspective}

AGRLs currently represent the GPCR with the most promiscuity in extracellular binding partners, which suggests multimodal regulation of their function. Studies with FLRTs in complex with both ADGRLs and Unc5 open a provocative idea that multimeric complex formation can differentially regulate ADGRL function. In contrast, specific comparisons between teneurins and FLRTs demonstrate that they both use a similar binding site on ADGRLs, suggesting that teneurins and FLRTs may not bind ADGRLs concurrently. Thus, it is 
likely that multimeric extracellular complexes extend well beyond this example to create large intercellular signalosomes with differential GPCR signaling outcomes. It is also plausible that selective expression patterns of synaptic adhesion molecules may dictate the components of the GPCR's extracellular complexing, thereby defining the signaling outcome of the receptor in a cell-specific and junction-specific manner.

\section{Direct Interaction of Adhesion G Protein-Coupled Receptor Subfamily G1/6 (G Protein-Coupled Receptor 56/126) with Extracellular Matrix Proteins Regulates Adhesion G Protein-Coupled Receptor Activation Mechanisms}

Adhesion GPCR subfamily G1 (ADGRG1; alternatively known as GPR56) has been recognized as a key element in the cortical development of the human frontal cortex (Piao et al., 2004). Mutations in the ADGRG1 gene are responsible for defects in neuronal migration and lamination processes that lead to morphologic defects of the cerebral cortex ( $\mathrm{Li}$ et al., 2008; Luo et al., 2011). More recently, ADGRG1 has been associated with oligodendrocyte development in the central nervous system and with peripheral nervous system development and maintenance (Ackerman et al., 2015, 2018). Peripherally, ADGRG1 has also been implicated in the function of pancreatic islet $\beta$ cells and the myoblast fusion process (Wu et al., 2013; Olaniru et al., 2018). At the G protein level, ADGRG1 has been shown to activate $\mathrm{G} \alpha_{12 / 13}$ initiating downstream RhoA activation to control neuronal progenitor migration (Luo et al., 2011, 2014; Stoveken et al., 2015). The crystal structure obtained from the ectodomain of ADGRG1 revealed a relatively uncharacterized putative extracellular protein-protein interaction domain labeled pentraxin/laminin/neurexin/ sex-hormone-binding-globulin-like (PLL) and a shorter GAIN domain deviating from the one found in prototypical adhesion GPCRs (Salzman et al., 2016). A closely related receptor, ADGRG6 (alternatively known as GPR126), has been identified as an evolutionarily conserved regulator of myelination in zebrafish Schwann cells (Monk et al., 2009). During development, ADGRG6 is able to elevate cAMP levels by coupling to heterotrimeric $\mathrm{G} \alpha_{\mathrm{s}}$ proteins, thereby regulating the expression of genes involved in the myelination process (Mogha et al., 2013). Furthermore, postnatal expression of ADGRG6 in Schwann cells has been associated with numerous aspects of peripheral nerve repair (Mogha et al., 2016). Structurally, the ADGRG6 ectodomain also contains a complement $\mathrm{C} 1 \mathrm{r} / \mathrm{C} 1 \mathrm{~s}$, Uegf, Bmp1 CUB domain, a pentraxin PTX domain, and a GAIN domain (Stehlik et al., 2004). Both ADGRG6 and ADGRG1 interact directly with critical components of the ECM and these events regulate cell adhesion and activation mechanisms of these GPCRs. In addition, $\mathrm{ADGRGs}$ have been suggested to interact with extracellular/transmembrane proteins such as integrin $\alpha 3 \beta 1$ (Jeong et al., 2013) and CD81/CD9 (Little et al., 2004; Chang et al., 2016); however, the nature of these interactions remains to be elucidated. The following ECM partners have been described.

\section{A. Collagen III}

Binding of collagen III to ADGRG1 provides a canonical example of adhesion GPCR interactions with ECM proteins (Luo et al., 2011). Identified by an in vitro biotinylation/proteomics approach, extracellular interactions with collagen III were subsequently proven capable of activating ADGRG1-mediated signaling via $\mathrm{G} \alpha_{12 / 13}$ followed by RhoA activation to regulate corticogenesis (Luo et al., 2011, 2014). Peripherally, collagen III induces ADGRG1-dependent calcium in pancreatic islet $\beta$ cells (Olaniru et al., 2018). Mechanistically, it is foreseeable that collagen III could act as a positive allosteric modulator to promote ligand-mediated effects of the ADGRG1 Stachel peptide tethered agonist (Stoveken et al., 2015), perhaps by aiding in removal of the ectodomain (Paavola et al., 2014). Structurally, collagen III assembles in a triple-helical structure stabilized by disulfide bonds, the common structural organization for all fibrillar collagens, and utilizes the ADGRG1 PLL domain for the interaction (Luo et al., 2012). This region of ADGRG1 also binds an important crosslinking enzyme of the ECM, transglutaminase-2, in a mutually exclusive manner with collagen III, suggesting that ADGRG1 activation is regulated dynamically dependent on the associated ECM partner (Xu et al., 2006). Interestingly, the presence of four alternative splicing isoforms in the ADGRG1 ectodomain, two of which include large deletions, further implicates a multilayered regulatory function that may differentiate ADGRG1 activation mechanisms beyond collagen IIImodulated signaling via the PLL domain (Bae et al., 2014).

\section{B. Collagen IV}

Collagen IV is a major structural constituent of the basal lamina and consists of an amino terminal 7S domain, a triple helix-forming collagenous domain, and a C-terminal noncollagenous NC1 domain (Brown et al., 2017). Collagen IV binds to ADGRG6 in the region of the CUB-PTX domains, similar to ADGRG1-collagen III complex formation. Collagen IV treatment of ADGRG6expressing HEK293 cells leads to an elevation in second messenger cAMP accumulation and it has been proposed that collagen IV interactions may provide positive allosteric modulation by aiding in the release of ADGRG6 ectodomain (Paavola et al., 2014), an event thought to be required for the activation of many adhesion GPCRs by exposing the Stachel peptide tethered agonist (Liebscher et al., 2014; Stoveken et al., 2015). A similar mechanism has been suggested for the transcellular interaction of adhesion GPCR ADGRE5 
with CD55 (Karpus et al., 2013). However, CD55-mediated removal of the ADGRE5 ectodomain instead induced ADGRE5 downregulation and it remains unclear whether induction of prototypical GPCR signaling is involved. Interestingly, collagen IV binding to ADGRG6 seems to be highly selective, as no association with other types of collagen was observed (Paavola et al., 2014). This complex formation precipitating removal of ectodomains presents a possible mechanism by which ECM proteins can directly regulate signaling of adhesion GPCRs.

\section{Laminin-211}

Laminins are ECM proteins organized as heterotrimeric complexes of $\alpha, \beta$, and $\gamma$ chains (Aumailley, 2013). Like collagens, laminins are critical components of the basal lamina where they mediate adhesion, cell migration, and cell differentiation (Aumailley, 2013). Unlike collagen IV, laminin-211 interacts with ADGRG6 within the GAIN domain to mediate myelination and the selection of individual axons for myelination, a process known as radial sorting (Petersen et al., 2015). Interestingly, the interaction of ADGRG6 with laminin-211 modulates a signaling response distinct from reactions reported to be initiated by collagen IV binding. Unlike collagen IV, application of laminin-211 to cells overexpressing ADGRG6 reduces cAMP by inhibiting its $\mathrm{G} \alpha_{\mathrm{S}}$ coupling (Petersen et al., 2015). Therefore, it was proposed that laminin-211 maintains ADGRG6 in an inactive state favoring static conditions and laminin polymerization in the ECM provides the dynamic force required to remove ADGRG6 ectodomain and subsequently activate canonical GPCR downstream signaling events (Petersen et al., 2015). Thus, laminin-211 extracellular interactions may provide negative allosteric modulation prior to laminin polymerization to suppress ADGRG6 signaling.

\section{Major Prion Protein}

Major prion protein $(\mathrm{PrP})$ is a GPI-anchored glycoprotein intimately involved with the ECM (Westergard et al., 2007) and has been implicated in the Schwann cell myelination process (Bremer et al., 2010). A study recently demonstrated that extracellular PrP was capable of modulating intracellular cAMP concentrations, thereby initiating a search culminating in the identification of ADGRG6 as its receptor (Küffer et al., 2016). It was shown that the flexible extracellular tail of $\operatorname{PrP}$ is sufficient to trigger a dose-dependent increase of cAMP levels in ADGRG6-expressing cells (Küffer et al., 2016). Interestingly, analysis of the $\mathrm{PrP}$ sequence revealed a polycationic cluster of amino acids within the ADGRG6binding motif that shares homology with collagen IV (Küffer et al., 2016), thereby illuminating common mechanisms that appear to be involved in the positive allosteric modulation of ADGRG6 activity by ECM proteins. Notably, PrP has also been found to bind mGluR5 and collectively form a coreceptor for amyloid- $\beta$-mediated calcium signaling (Um et al., 2013). Therefore, it is foreseeable that PrP, and perhaps other ECM components described above, may act on other GPCRs beyond ADGRG1/6 to modulate their activity either directly or through formation of coreceptor complexes.

\section{E. Perspective}

Collectively, it is now abundantly clear that the ECM cannot be simply considered as a structural network of extracellular scaffolding. The direct interaction of a variety of ECM components with ADGRG1/6 is dynamically involved in both positive and negative modulation of canonical GPCR signaling pathways. The action of ECM on the GPCR ectodomains can facilitate subsequent receptor activation or keep it in an inactive conformation. Given these observations, it appears highly convincing that the continuum of ADGRG signaling can be both dynamically and directly regulated by the ECM, and these mechanisms must be considered as we advance our understanding of ADGRG pharmacology.

\section{Bidirectional Transsynaptic Coordination of Signaling Involving Complexes Composed of Adhesion G Protein-Coupled Receptor B1-3 (Brain-Specific Angiogenesis Inhibitor 1-3)}

Adhesion GPCR subfamily B1-3 (ADGRB1-3; alternatively known as brain-specific angiogenesis inhibitor 1-3) is composed of brain-enriched postsynaptic adhesion GPCRs implicated in central synapse formation and lesser peripheral expression in the heart and skeletal muscle where they have been implicated in the myoblast fusion process (Cork and Van Meir, 2011; Duman et al., 2013; Hamoud et al., 2014; Kakegawa et al., 2015; Sigoillot et al., 2015; Martinelli et al., 2016). Similar to ADGRLs, ADGRBs have been demonstrated to initiate canonical $\mathrm{G}$ protein activation pathways and subsequent intracellular signaling cascades (Park et al., 2007; Lanoue et al., 2013; Stephenson et al., 2013; Hamoud et al., 2014). Accordingly, modulation of this process via extracellular interacting partners posits heavy implications in adhesion GPCR signaling and physiology. As with many adhesion GPCRs, ADGRB ectodomains feature conserved domains such as four to five thrombospondin repeats, a hormone-binding HB domain, and a membrane proximal GAIN domain. In addition, ADGRB3 comprises a unique CUB domain. Through their multimodular ectodomains, ADGRBs have been shown to interact with multiple extracellular proteins to regulate both cell autonomous and noncell autonomous functions to coordinate both pre- and postsynaptic processes as detailed below.

\section{A. Complement C1q-Like 1-4}

The C1q-like family is composed of brain-enriched, presynaptically secreted proteins that form homo- and heteromeric complexes (Iijima et al., 2010; Yuzaki, 2010; 
Martinelli et al., 2016). Physiologic roles in the central nervous system and in peripheral tissues have been clearly established for some members of the family. C1ql1 was shown to modulate Purkinje cell spinogenesis necessary for motor learning (Kakegawa et al., 2015; Sigoillot et al., 2015). In addition, C1ql3 was shown to be involved in synapse formation/maintenance underlying formation of fear memories (Martinelli et al., 2016). Peripherally, C1ql3 inhibits insulin secretion in pancreatic $\beta$ cells (Gupta et al., 2018), whereas C1q14 acts as a repressor of myoblast fusion (Hamoud et al., 2014) and was recently identified as a novel regulator of testosterone secretion in the testis (Tan et al., 2019). ADGRB3 utilizes selective domains to engage with different $\mathrm{C} 1 \mathrm{ql}$ proteins. For example, the thrombospondin repeat domains in the ADGRB3 ectodomain are both necessary and sufficient for the interaction with C1ql3 (Bolliger et al., 2011), whereas the interaction with the homolog C1ql1 in the cerebellum is mediated instead by the CUB domain (Kakegawa et al., 2015). Notably, C1ql proteins interact with the ADGRB3 ectodomain in a $\mathrm{Ca}^{2+}$-dependent fashion (Bolliger et al., 2011), suggesting the possibility of dynamic binding events and feeding a hypothesis that C1qls could mediate their physiologic effects by directly modulating ADGRB signaling properties. For instance, C1ql4 could act as a negative allosteric modulator by stabilizing the inactive conformation of ADGRB3 to limit G protein signaling (Hamoud et al., 2014), perhaps competing with the positive modulator of ADGRB3 signaling: stabilin-2.

\section{B. Stabilin-2}

The single-pass transmembrane receptor stabilin-2 is a key element in myoblast fusion, an essential step in the development of skeletal muscle myofibers (Park et al., 2016). Stabilin-2 has been shown to interact with ADGRB3 in cis. Interestingly, ADGRB3's interaction with stabilin-2 or C1ql4 appears to be mutually exclusive, acting as a molecular switch to activate or suppress myoblast fusion, respectively (Hamoud et al., 2014). Mechanistically, the coexpression of ADGRB3 with stabilin-2 promotes $\mathrm{G}$ protein activation and the accumulation of second messenger could help facilitate the observed myoblast fusion events. In contrast, C1ql4 has been proposed to stabilize ADGRB3 in an inactive conformation, thereby limiting $\mathrm{G}$ protein signaling and fusion events (Hamoud et al., 2014). Collectively, it appears that ADGRBs are capable of hosting multiple extracellular binding partners to either positively or negatively modulate signaling events, thereby providing a molecular mechanism to regulate postsynaptic spinogenesis in the central nervous system.

\section{Neuroligin-1}

Neuroligin-1 is known as a powerful regulator of excitatory synapse formation and maturation that acts by making transsynaptic contacts with neurexin family members (Scheiffele et al., 2000), yet recent studies have identified a novel interaction in cis between neuroligin-1 and ADGRB1 (Tu et al., 2018). One physiologic role of the ADGRB1 ectodomain, possibly mediated by such interactions, consists of its ability to promote spinogenesis and excitatory synaptogenesis (Duman et al., 2013; Tu et al., 2018). Interestingly, postsynaptic ADGRB1 is also capable of inducing presynaptic differentiation, suggesting that this GPCR can further be involved in retrograde signal transmission across the synaptic cleft (Tu et al., 2018). Because neuroligin-1 is a well established transsynaptic binding partner of neurexins, it was hypothesized that postsynaptic ADGRB1 may coordinate pre- and postsynaptic processes via its interaction with neuroligin1-neurexin transsynaptic complexes (Tu et al., 2018). In this model, ADGRB signaling could be modulated via extracellular interactions with neuroligin-1 in cis to facilitate postsynaptic spinogenesis. The impact of neuroligin-1 on ADGRB signaling could be further modified by conformational changes induced by interactions with neurexin in trans. It is also possible that ADGRB-dependent signaling could be transduced in a retrograde-manner presynaptically depending on interactions within the neuroligin-1-neurexin transcomplex, thereby providing a mechanism for coordinating pre- and postsynaptic actions during synaptogenesis. However, this hypothesized retrograde mechanism remains to be established.

\section{Perspective}

Observations reported for ADGRB reinforce the view that activation and inactivation mechanisms of GPCRs may be closely linked to their extracellular interactions. It is possible that the identity of components forming particular complexes could differentially contribute to regulation of the ADGRB along the signaling continuum. For example, stabilin-2 interactions in cis may act as positive allosteric modulators of $\mathrm{G}$ protein signaling of ADGRB, whereas interactions with C1qls may act as negative allosteric modulators to stabilize the receptors in the inactive confirmation. These transitions may be dynamic, as suggested by the $\mathrm{Ca}^{2+}$ dependence of some of these interactions. Furthermore, the diversity of proteins found to bind the ADGRB ectodomain at alternative binding sites may further complicate the functional regulation by allowing their synergistic or antagonistic interactions. Finally, ADGRBs may be involved in bidirectional coordination of signaling across the synaptic cleft, as evidenced by the ADGRB1 ectodomain inducing antiproliferative and antiangiogenic effects via integrin $\alpha_{\mathrm{V}} \beta_{5}$ and CD36 (Koh et al., 2004; Kaur et al., 2009). The intriguing possibility of retrograde signaling initiated by ADGRBs but converted into the cellular signaling outcomes by other 
components of the complexes will need to be better defined mechanistically.

\section{Assembly of Transsynaptic Complexes with Orphan G Protein-Coupled Receptor 158/179 Facilitates Bidirectional Scaffolding of Intracellular Signaling Molecules}

Related orphan receptors GPR158 and GPR179 were recently found to play key roles in regulating intracellular signaling pathways crucially involved in fundamental behaviors. For instance, GPR158 is emerging as a key player in mood control (Sutton et al., 2018; Orlandi et al., 2019) and cognition (Khrimian et al., 2017; Condomitti et al., 2018), acting in the prefrontal cortex and hippocampus, respectively, whereas GPR179 in the retina has been noted for its indispensable role in dim vision (Audo et al., 2012; Orlandi et al., 2012; Peachey et al., 2012). Transmembrane domains of both GPR158 and GPR179 identify most closely with class C GPCRs (Bjarnadóttir et al., 2005). In addition, these receptors feature large extracellular amino termini that do not resemble those of other GPCRs from this group. Instead of a Venus flytrap domain, the canonical ligand-binding structure for class C GPCRs, GPR158 and GPR179 have conserved sequences that are most commonly found in adhesion GPCRs such as an EGFlike $\mathrm{Ca}^{2+}$-binding domain and a short leucine repeat (Orlandi et al., 2012). The high homology of sequence between GPR158 and GPR179 suggests that they could share similar functional properties, yet expression pattern analysis revealed that GPR179 is selectively expressed in the mammalian retina, whereas GPR158 is widely expressed in the brain, including in the prefrontal cortex and hippocampus (Orlandi et al., 2012; Khrimian et al., 2017; Condomitti et al., 2018; Sutton et al., 2018). It has been suggested that in the hippocampus, GPR158 may be activated by interaction with a peptide hormone osteocalcin to signal via a $\mathrm{G} \alpha_{\mathrm{q}}$ (Khrimian et al., 2017). However, further studies are needed to establish whether $G$ proteins are indeed direct substrates of GPR158/179 actions and whether there are additional ligands and/or activation reactions. Uniquely, both GPR158 and GPR179 have been shown to serve as membrane anchors for a neuronal-enriched family of regulator of $G$ protein signaling (RGS) proteins involved in many neurophysiological processes (Orlandi et al., 2012, 2015). Through proteomic screening, GPR158 and GPR179 ectodomains were recently found to interact with several members of the heterogenous family of cell-surface and secreted heparan sulfate proteoglycans (HSPGs) (Condomitti et al., 2018; Orlandi et al., 2018). HSPGs are abundant components of the cell surface with contributions to the structure of the ECM and the distribution of extracellular signaling molecules (Sarrazin et al., 2011; Condomitti and de Wit, 2018). Emerging discoveries increasingly point at HSPGs as regulators of synaptic connectivity (Sarrazin et al., 2011; Condomitti and de Wit, 2018); their promiscuous interactions with a variety of binding partners, together with a restricted expression pattern for each member of the family, make HSPG complexes an extremely powerful way to generate synaptic specificity. Two such partners have been characterized extensively, providing the following information.

\section{A. Pikachurin}

In the retina, GPR179 is specifically localized at the dendritic tips of ON-bipolar neurons that make direct synaptic contacts with the presynaptic photoreceptors (Audo et al., 2012). The ectodomain of GPR179 has been shown to interact with the HSPG pikachurin (Orlandi et al., 2018). Pikachurin features a modular composition with two FN3 domains at the amino terminus and three laminin G domains separated by two EGF-like domains in the carboxyl terminus. Pikachurin is a secreted protein released by photoreceptors. It is a component of the presynaptic dystrophin-associated glycoprotein complex (DGC) involved in the synaptic communication of photoreceptors (Sato et al., 2008). The interaction of GPR179 with pikachurin does not require heparan sulfate (HS) modification because removal of HS chains does not disrupt the binding. Instead, the interaction site comprises the last EGF-laminin G domain region of pikachurin (Orlandi et al., 2018). Notably, transsynaptic interaction of the DGC complex with GPR179 mediated by pikachurin plays essential role for the postsynaptic targeting of GPR179 and ablation of pikachurin disrupts GPR179 protein stability (Orlandi et al., 2018). As a consequence, the localization of RGS proteins scaffolded by GPR179 on the postsynaptic site is compromised (Orlandi et al., 2018). This deficit leads to slowing of the synaptic transmission speed, as RGS proteins are essential components of the postsynaptic signaling machinery that drives postsynaptic depolarization (Orlandi et al., 2012; Sarria et al., 2016). Taken together, these observations suggest that pikachurin acts as an integral scaffold of the postsynaptic GPR179-RGS complex to influence unique postsynaptic signaling and neurotransmission. Additional anchoring of pikachurin by presynaptic DGC enables it to serve as a transsynaptic bridge in coordinating function of synaptic macromolecular complexes involved in transmission of the signal.

\section{B. Glypican 4}

Glypicans (GPC1-GPC6) are evolutionary conserved proteins similar in size and characterized by the presence of several intramolecular disulfide bonds critical in defining their three-dimensional structure. Unlike pikachurin, GPC4 is a GPI-anchored extracellular protein that acts as a presynaptic regulator of excitatory synapse formation with the capability of forming transsynaptic 


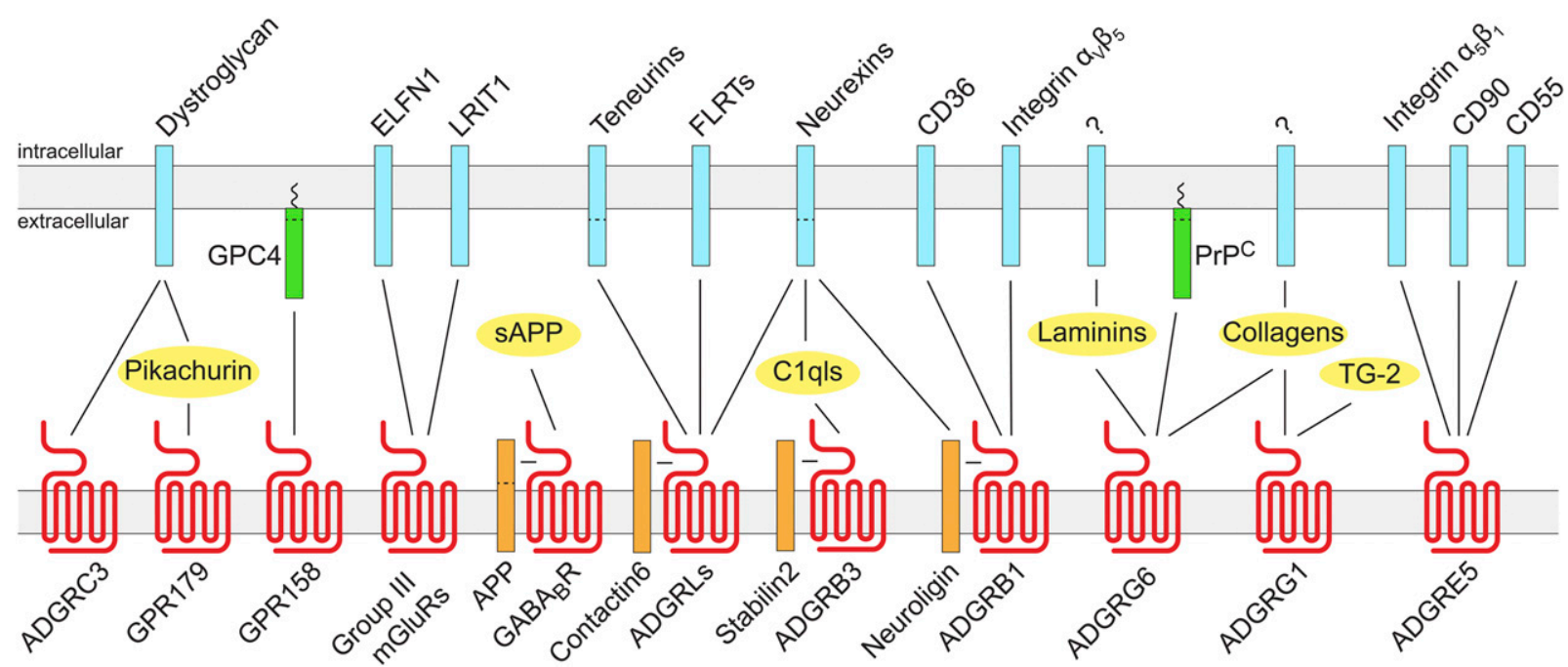

Fig. 2. The diversity and complexity of the GPCR extracellular interactome suggests functional and structural roles beyond traditional ligand activation. A multitude of proteins create direct or indirect links in cis and in trans with GPCR ectodomains. Proteins are represented schematically, and arrows represent validated protein-protein interactions of functional consequence.

complexes with a variety of adhesion molecules (de Wit et al., 2013; Siddiqui et al., 2013). Interestingly, GPR158 expressed in hippocampal CA3 pyramidal neurons is selectively localized at postsynaptic sites in the proximal segment that receive inputs from mossy fiber where GPR158 has been demonstrated to interact with GPC4 in trans (Condomitti et al., 2018). Such organization allows GPR158 to induce presynaptic differentiation and regulate the spine density in an input-specific manner (Condomitti et al., 2018). These important organizational events of the synapse are mediated by GPR158-specific transsynaptic interactions with GPC4 and require the recruitment of an additional presynaptic partner by GPC4: leukocyte antigen-related (LAR) tyrosine phosphatase (Condomitti et al., 2018). In contrast to the GPR179-pikachurin interaction, GPR158-GPC4 binding was found to be HS dependent, as enzymatic removal of HS or mutation of the HS-modified amino acids disrupted the interaction (Condomitti et al., 2018), suggestive of a possible dynamic modulation of the interaction by changes in posttranslational modification status. The ability of the GPR158 ectodomain to induce presynaptic differentiation in contacting axons does not require its EGF-like nor leucin repeat domain (Condomitti et al., 2018). Collectively, GPR158 organizes both the postsynaptic density ultrastructure and the presynaptic active zone for neurotransmitter release, presumably by its control over the presynaptic GPC4-LAR complex.

\section{Perspective}

Orphan GPCRs remain elusive in our pursuit to fully understand GPCR pharmacology; however, the identification of transsynaptic HSPG binding partners and examples of their necessity for adequate localization of constituent signaling complexes paves a way for interrogating activation mechanisms and cellular roles of
GPR158 and GPR179 and possibly other orphan GPCRs featuring ectodomains with protein-protein interaction motifs. The involvement of GPR158/179 in the formation of transsynaptic complexes, together with the ability of their HSPG partners to scaffold other signaling molecules in cis, suggests an intriguing possibility of extracellular scaffolding involved in bidirectional modulation of intracellular signaling on both sides of opposing synaptic membranes. For example, HSPGs may direct targeting of GPR158/179 and ensuing assembly of signaling complexes involving RGS proteins on the postsynaptic side, whereas GPR158/179 may reciprocally contribute to presynaptic organization of HSPG complexes with signaling mediators (e.g., LAR) to form a higherorder transsynaptic GPCR signalosomes.

\section{Concluding Remarks}

The evidence compiled above strongly suggests that the emerging concepts of extracellular and transcellular interactions in GPCR regulation (Fig. 2) provide a comparable degree of diversity to the well characterized intracellular modulation of GPCR function. Functions of adhesion GPCRs have been heavily linked with extracellular biology, yet the recent inclusion of class C GPCRs in these novel structural complexes suggests that class C GPCRs, or GPCRs with large extracellular domains in general, may similarly possess adhesion GPCR-like properties and be subject to a variety of extracellular modulators that remain to be characterized. Furthermore, these interactions have proven relevant to a subset of orphan GPCRs and may provide a blueprint for our understanding of the unusual biology of these understudied receptors. Beyond structural implications, it is important to consider that extracellular interacting partners can endow the GPCR with specific functional consequences, seemingly acting as 
TABLE

Functional consequence of extracellular interactions with GPCRs

\begin{tabular}{|c|c|c|c|c|}
\hline $\begin{array}{l}\text { Receptor (Alternate } \\
\text { Name) }\end{array}$ & Partner & Structure & Functional Consequences of Extracellular GPCR Interaction & Reference \\
\hline ADGRL1 (LPHN1) & Contactin-6 & Cis & Role in neurite outgrowth and apoptosis & Zuko et al. (2016) \\
\hline ADGRL1 (LPHN1) & Teneurin-2 & $\begin{array}{l}\text { Trans/ } \\
\text { soluble }\end{array}$ & $\begin{array}{l}\text { Synaptogenic interaction. Purified teneurin- } 2 \text { ectodomain } \\
\text { induces } \mathrm{Ca}^{2+} \text { release in presynaptic boutons of } \\
\text { hippocampal neurons }\end{array}$ & Silva et al. (2011) \\
\hline ADGRL1 (LPHN1) & Teneurin-2 & $\begin{array}{l}\text { Trans/ } \\
\text { soluble }\end{array}$ & $\begin{array}{l}\text { Role in axonal attraction and fasciculation. Functional role in } \\
\text { neuromuscular junction transmission }\end{array}$ & Vysokov et al. (2018) \\
\hline ADGRL1 (LPHN1) & Teneurin-2 & $\begin{array}{l}\text { Trans/ } \\
\text { soluble }\end{array}$ & $\begin{array}{l}\text { Interaction in trans alters cAMP accumulation in ADGRL1- } \\
\text { expressing cells }\end{array}$ & Li et al. (2018) \\
\hline ADGRL1-3 (LPHN1-3) & $\begin{array}{l}\text { Teneurin-2, } \\
\text { teneurin-4 }\end{array}$ & $\begin{array}{l}\text { Trans/ } \\
\text { soluble }\end{array}$ & $\begin{array}{l}\text { Induces cellular aggregation and junction formation. } \\
\text { Interruption of interaction decreases synaptic density in } \\
\text { cultured neurons }\end{array}$ & Boucard et al. (2014) \\
\hline ADGRL1-3 (LPHN1-3) & FLRT3 & Trans & $\begin{array}{l}\text { Interruption of interaction decreases synaptic density in } \\
\text { cultured neurons }\end{array}$ & Boucard et al. (2014) \\
\hline ADGRL1 (LPHN1) & FLRT3 & Trans & $\begin{array}{l}\text { Role in defining excitatory synapse density, afferent input } \\
\text { strength, and dendritic spine number }\end{array}$ & O'Sullivan et al. (2012) \\
\hline ADGRL3 (LPHN3) & FLRT2 & Trans & $\begin{array}{l}\text { Interaction facilitates adhesion in HeLa cells and repulsion in } \\
\text { cortical neurons }\end{array}$ & Jackson et al. (2015) \\
\hline ADGRL1 (LPHN1) & FLRT2 & Trans & Complex with Unc5D inhibits cell adhesion & Jackson et al. (2016) \\
\hline ADGRL1 (LPHN1) & NRXN1 & Trans & $\begin{array}{l}\text { ADGRL1 competes with neuroligin to form a transcellular } \\
\text { adhesion complex with neurexin }\end{array}$ & Boucard et al. (2012) \\
\hline ADGRC3 (CELSR3) & Dystroglycan & Trans & Role in axon guidance & Lindenmaier et al. (2019) \\
\hline ADGRB3 (BAI3) & $\mathrm{C} 1 \mathrm{ql} 3$ & Soluble & $\mathrm{Ca}^{2+}$-dependent interaction with TSRs in ADGRB3 ectodomain & Bolliger et al. (2011) \\
\hline ADGRB3 (BAI3) & C1ql1 & Soluble & Role in motor learning at climbing fiber-Purkinje cell synapses & Kakegawa et al. (2015) \\
\hline ADGRB3 (BAI3) & C1ql1 & Soluble & $\begin{array}{l}\text { C1ql1's modulation of Purkinje cell spinogenesis is } \\
\text { ADGRB3 dependent }\end{array}$ & Sigoillot et al. (2015) \\
\hline ADGRB3 (BAI3) & C1ql4 & Soluble & C1ql4 interacts with ADGRB3 to suppress myoblast fusion & Hamoud et al. (2014) \\
\hline ADGRB3 (BAI3) & Stabilin-2 & Cis & $\begin{array}{l}\text { Stabilin-2 interacts in cis to promote } \mathrm{G} \text { protein activation via } \\
\text { ADGRB3 and activate myoblast fusion }\end{array}$ & Hamoud et al. (2014) \\
\hline ADGRB1 (BAI1) & Neuroligin-1 & Cis & $\begin{array}{l}\text { Role in spinogenesis, excitatory synaptogenesis, and } \\
\text { presynaptic clustering of vGlut1 with neuroligin-neurexin } \\
\text { transcomplex }\end{array}$ & Tu et al. (2018) \\
\hline ADGRB1 (BAI1) & Integrin $\alpha_{\mathrm{V}} \beta_{5}$ & Trans & $\begin{array}{l}\text { ADGRB1 ectodomain shows antiproliferative effects by blocking } \\
\alpha_{\mathrm{V}} \beta_{5} \text { integrin }\end{array}$ & Koh et al. (2004) \\
\hline ADGRB1 (BAI1) & CD36 & Trans & $\begin{array}{l}\text { ADGRB1 released ectodomain mediates antivascular effects by } \\
\text { interacting with CD36 }\end{array}$ & Kaur et al. (2009) \\
\hline ADGRE5 (CD97) & CD55 & Trans & Role in cell adhesion & Hamann et al. (1996) \\
\hline ADGRE5 (CD97) & CD55 & Trans & Promotes receptor desensitization after ectodomain cleavage & Karpus et al. (2013) \\
\hline ADGRE5 (CD97) & CD90 & Trans & $\begin{array}{l}\text { Role in leukocyte adhesion to activated endothelium during } \\
\text { inflammatory processes }\end{array}$ & Wandel et al. (2012) \\
\hline ADGRE5 (CD97) & Integrin $\alpha_{5} \beta_{1}$ & Trans & $\begin{array}{l}\text { Interaction initiates endothelial cell invasion by } \\
\text { inflammatory cells }\end{array}$ & Wang et al. (2005) \\
\hline ADGRG1 (GPR56) & Collagen III & Soluble & $\begin{array}{l}\text { Promotes ADGRG1-dependent calcium signaling in pancreatic } \\
\text { islet } \beta \text { cells }\end{array}$ & Olaniru et al. (2018) \\
\hline ADGRG1 (GPR56) & Collagen III & Soluble & $\begin{array}{l}\text { Interaction activates } \mathrm{G} \alpha_{12 / 13}-\mathrm{RhoA} \text { to control neuronal } \\
\text { progenitor migration and corticogenesis }\end{array}$ & Luo et al. $(2011,2014)$ \\
\hline ADGRG6 (GPR126) & Collagen IV & Soluble & $\begin{array}{l}\text { Collagen IV treatment of ADGRG6-expressing cells } \\
\text { increases cAMP }\end{array}$ & Paavola et al. (2014) \\
\hline ADGRG6 (GPR126) & Laminin-211 & Soluble & $\begin{array}{l}\text { Laminin- } 211 \text { promotes myelination through ADGRG6 in vivo. } \\
\text { Interaction reduces cAMP via ADGRG6 }\end{array}$ & Petersen et al. (2015) \\
\hline ADGRG6 (GPR126) & $\operatorname{PrP}$ & Soluble & PrP activates ADGRG6 to increase cAMP & Küffer et al. (2016) \\
\hline GPR179 & Pikachurin & Soluble & $\begin{array}{l}\text { Pikachurin recruits GPR179-RGS complex to photoreceptor } \\
\text { postsynaptic sites }\end{array}$ & Orlandi et al. (2018) \\
\hline GPR158 & Glypican4 & Trans & $\begin{array}{l}\text { Role in presynaptic differentiation and defining input-specific } \\
\text { synaptic properties at mossy fiber-CA3 synapses in } \\
\text { hippocampus }\end{array}$ & Condomitti et al. (2018) \\
\hline mGluR7 & ELFN1 & Trans & Soluble ectodomain promotes constitutive activity & Stachniak et al. (2019) \\
\hline mGluR7 & ELFN1 & Trans & Role in synaptic targeting of mGluR7 & Tomioka et al. (2014) \\
\hline mGluR6 & ELFN1 & Trans & Role in promoting mGluR6 expression and synaptic targeting & Cao et al. (2015) \\
\hline mGluR4/6 & ELFN1 & Trans & $\begin{array}{l}\text { Allosteric modulation of mGluR } 4 / 6 \text { via } G \text { protein coupling } \\
\text { mechanisms. Promotes constitutive activity }\end{array}$ & Dunn et al. (2018) \\
\hline $\mathrm{GABA}_{\mathrm{B}} \mathrm{R} 1 \mathrm{a}$ & $\mathrm{APP} / \mathrm{sAPP}$ & Soluble & $\begin{array}{l}\text { Modulates } \mathrm{GABA}_{\mathrm{B}} \mathrm{R} 1 \mathrm{a} \text { axonal trafficking and signaling to } \\
\text { decrease vesicle release probability }\end{array}$ & $\begin{array}{l}\text { Dinamarca et al. (2019), } \\
\text { Rice et al. (2019) }\end{array}$ \\
\hline
\end{tabular}

BAI, brain-specific angiogenesis inhibitor; LPHN, latrophilin; TSR, thrombospondin repeat.

either positive or negative allosteric modulators of the GPCR response to ligand-mediated effects (Table 1). It is now clear that transcellular interactions are involved in adjusting pharmacological properties of GPCRs and therefore must be considered and exploited in drug discovery efforts. Just as cell-specific effects of drug action have been implicated, it is foreseeable that the differential expression patterns of extracellular proteins at different cellular and synaptic junctions could provide diverse functional consequences for the GPCR that alter pharmacological responses to drugs in a cellspecific and junction-specific manner. Furthermore, this 
concept of the extracellular dimension of GPCRs introduces an added complexity to our understanding of cell junction/synapse formation and the possibility of novel cell-to-cell communication mechanisms that remain to be fully elucidated. With the combined efforts of multiple research groups, the characterization of transcellular/ transsynaptic regulation of GPCRs by a variety of extracellular proteins is proving to be a new dimension in the central dogma of GPCR function and pharmacology.

\section{Acknowledgments}

We thank Dr. Hannah M. Stoveken (The Scripps Research Institute, Jupiter, FL) for critical comments on the manuscript.

\section{Authorship Contributions}

Wrote or contributed to the writing of the manuscript: Dunn, Orlandi, Martemyanov.

\section{References}

Ackerman SD, Garcia C, Piao X, Gutmann DH, and Monk KR (2015) The adhesion GPCR Gpr56 regulates oligodendrocyte development via interactions with $\mathrm{G} \alpha 12 / 13$ and RhoA. Nat Commun 6:6122.

Ackerman SD, Luo R, Poitelon Y, Mogha A, Harty BL, D’Rozario M, Sanchez NE, Lakkaraju AKK, Gamble P, Li J, et al. (2018) GPR56/ADGRG1 regulates development and maintenance of peripheral myelin. $J$ Exp Med 215:941-961.

Acosta MT, Swanson J, Stehli A, Molina BS, Martinez AF, Arcos-Burgos M, and Muenke M; MTA Team (2016) ADGRL3 (LPHN3) variants are associated with a refined phenotype of ADHD in the MTA study. Mol Genet Genomic Med 4 $540-547$.

Amalric M, Lopez S, Goudet C, Fisone G, Battaglia G, Nicoletti F, Pin JP, and Acher FC (2013) Group III and subtype 4 metabotropic glutamate receptor agonists: discovery and pathophysiological applications in Parkinson's disease. Neuropharmacology 66:53-64.

Anderson GR, Maxeiner S, Sando R, Tsetsenis T, Malenka RC, and Südhof TC (2017) Postsynaptic adhesion GPCR latrophilin-2 mediates target recognition in entorhinal-hippocampal synapse assembly. J Cell Biol 216:3831-3846.

Araç D, Boucard AA, Bolliger MF, Nguyen J, Soltis SM, Südhof TC, and Brunger AT (2012) A novel evolutionarily conserved domain of cell-adhesion GPCRs mediates autoproteolysis. EMBO $J$ 31:1364-1378.

Araç D, Sträter N, and Seiradake E (2016) Understanding the structural basis of adhesion GPCR functions. Handb Exp Pharmacol 234:67-82

Arcos-Burgos M, Jain M, Acosta MT, Shively S, Stanescu H, Wallis D, Domené S, Vélez JI, Karkera JD, Balog J, et al. (2010) A common variant of the latrophilin 3 gene, LPHN3, confers susceptibility to ADHD and predicts effectiveness of stimulant medication. Mol Psychiatry 15:1053-1066.

Audo I, Bujakowska K, Orhan E, Poloschek CM, Defoort-Dhellemmes S, Drumare I, Kohl S, Luu TD, Lecompte O, Zrenner E, et al. (2012) Whole-exome sequencin identifies mutations in GPR179 leading to autosomal-recessive complete congenital stationary night blindness. Am J Hum Genet 90:321-330.

Aumailley M (2013) The laminin family. Cell Adhes Migr 7:48-55.

Bae BI, Tietjen I, Atabay KD, Evrony GD, Johnson MB, Asare E, Wang PP, Murayama AY, Im K, Lisgo SN, et al. (2014) Evolutionarily dynamic alternative splicing of GPR56 regulates regional cerebral cortical patterning. Science 343: $764-768$.

Becker JA, Clesse D, Spiegelhalter C, Schwab Y, Le Merrer J, and Kieffer BL (2014) Autistic-like syndrome in mu opioid receptor null mice is relieved by facilitated mGluR4 activity. Neuropsychopharmacology 39:2049-2060.

Biermann B, Ivankova-Susankova K, Bradaia A, Abdel Aziz S, Besseyrias V, Kapfhammer JP, Missler M, Gassmann M, and Bettler B (2010) The sushi domains of GABAB receptors function as axonal targeting signals. J Neurosci 30:1385-1394.

Bjarnadóttir TK, Fredriksson R, and Schiöth HB (2005) The gene repertoire and the common evolutionary history of glutamate, pheromone (V2R), taste(1) and other related G protein-coupled receptors. Gene 362:70-84.

Blein S, Ginham R, Uhrin D, Smith BO, Soares DC, Veltel S, McIlhinney RA, White $\mathrm{JH}$, and Barlow PN (2004) Structural analysis of the complement control protein (CCP) modules of GABA(B) receptor 1a: only one of the two CCP modules is compactly folded. J Biol Chem 279:48292-48306.

Bolliger MF, Martinelli DC, and Südhof TC (2011) The cell-adhesion G proteincoupled receptor BAI3 is a high-affinity receptor for C1q-like proteins. Proc Natl Acad Sci USA 108:2534-2539.

Boucard AA, Ko J, and Südhof TC (2012) High affinity neurexin binding to cell adhesion G-protein-coupled receptor CIRL1/latrophilin-1 produces an intercellular adhesion complex. J Biol Chem 287:9399-9413.

Boucard AA, Maxeiner S, and Südhof TC (2014) Latrophilins function as heterophilic cell-adhesion molecules by binding to teneurins: regulation by alternative splicing. $J$ Biol Chem 289:387-402.

Bowery NG (2006) GABAB receptor: a site of therapeutic benefit. Curr Opin Pharmacol 6:37-43.

Bremer J, Baumann F, Tiberi C, Wessig C, Fischer H, Schwarz P, Steele AD, Toyka $\mathrm{KV}$, Nave KA, Weis J, et al. (2010) Axonal prion protein is required for peripheral myelin maintenance. Nat Neurosci 13:310-318.
Brown KL, Cummings CF, Vanacore RM, and Hudson BG (2017) Building collagen IV smart scaffolds on the outside of cells. Protein Sci 26:2151-2161.

Bruxel EM, Salatino-Oliveira A, Akutagava-Martins GC, Tovo-Rodrigues L, Genro JP, Zeni CP, Polanczyk GV, Chazan R, Schmitz M, Arcos-Burgos M, et al. (2015) LPHN3 and attention-deficit/hyperactivity disorder: a susceptibility and pharmacogenetic study. Genes Brain Behav 14:419-427.

Caillé I, Allinquant B, Dupont E, Bouillot C, Langer A, Müller U, and Prochiantz A (2004) Soluble form of amyloid precursor protein regulates proliferation of progenitors in the adult subventricular zone. Development 131:2173-2181.

Cao Y, Sarria I, Fehlhaber KE, Kamasawa N, Orlandi C, James KN, Hazen JL, Gardner MR, Farzan M, Lee A, et al. (2015) Mechanism for selective synaptic wiring of rod photoreceptors into the retinal circuitry and its role in vision. Neuron 87:1248-1260

Chang GW, Hsiao CC, Peng YM, Vieira Braga FA, Kragten NA, Remmerswaal EB, van de Garde MD, Straussberg R, König GM, Kostenis E, et al. (2016) The adhesion G protein-coupled receptor GPR56/ADGRG1 is an inhibitory receptor on human NK cells. Cell Rep 15:1757-1770.

Condomitti $\mathrm{G}$ and de Wit J (2018) Heparan sulfate proteoglycans as emerging players in synaptic specificity. Front Mol Neurosci 11:14.

Condomitti G, Wierda KD, Schroeder A, Rubio SE, Vennekens KM, Orlandi C, Martemyanov KA, Gounko NV, Savas JN, and de Wit J (2018) An input-specific orphan receptor GPR158-HSPG interaction organizes hippocampal mossy fiberCA3 synapses. Neuron 100:201-215.e9.

Cork SM and Van Meir EG (2011) Emerging roles for the BAI1 protein family in the regulation of phagocytosis, synaptogenesis, neurovasculature, and tumor development. J Mol Med (Berl) 89:743-752.

Davletov BA, Shamotienko OG, Lelianova VG, Grishin EV, and Ushkaryov YA (1996) Isolation and biochemical characterization of a $\mathrm{Ca}^{2+}$-independent alpha-latrotoxinbinding protein. J Biol Chem 271:23239-23245.

De Strooper B, Vassar R, and Golde T (2010) The secretases: enzymes with therapeutic potential in Alzheimer disease. Nat Rev Neurol 6:99-107.

de Wit J, O'Sullivan ML, Savas JN, Condomitti G, Caccese MC, Vennekens KM, Yates JR 3rd, and Ghosh A (2013) Unbiased discovery of glypican as a receptor for LRRTM4 in regulating excitatory synapse development. Neuron 79:696-711.

Dinamarca MC, Raveh A, Schneider A, Fritzius T, Früh S, Rem PD, Stawarski M, Lalanne T, Turecek R, Choo M, et al. (2019) Complex formation of APP with $\mathrm{GABA}_{\mathrm{B}}$ receptors links axonal trafficking to amyloidogenic processing. Nat Commun 10:1331.

Duman JG, Tzeng CP, Tu YK, Munjal T, Schwechter B, Ho TS, and Tolias KF (2013) The adhesion-GPCR BAI1 regulates synaptogenesis by controlling the recruitment of the Par3/Tiam1 polarity complex to synaptic sites. J Neurosci 33:6964-6978.

Dunn HA and Ferguson SSG (2015) PDZ protein regulation of G protein-coupled receptor trafficking and signaling pathways. Mol Pharmacol 88:624-639.

Dunn HA, Patil DN, Cao Y, Orlandi C, and Martemyanov KA (2018) Synaptic adhesion protein ELFN1 is a selective allosteric modulator of group III metabotropic glutamate receptors in trans. Proc Natl Acad Sci USA 115:5022-5027.

Eichel K and von Zastrow M (2018) Subcellular organization of GPCR signaling. Trends Pharmacol Sci 39:200-208.

Folts CJ, Giera S, Li T, and Piao X (2019) Adhesion G protein-coupled receptors as drug targets for neurological diseases. Trends Pharmacol Sci 40:278-293.

Furukawa K, Barger SW, Blalock EM, and Mattson MP (1996) Activation of K+ channels and suppression of neuronal activity by secreted beta-amyloid-precursor protein. Nature 379:74-78

Geng Y, Xiong D, Mosyak L, Malito DL, Kniazeff J, Chen Y, Burmakina S, Quick M, Bush M, Javitch JA, et al. (2012) Structure and functional interaction of the extracellular domain of human GABA(B) receptor GBR2. Nat Neurosci 15:970-978.

Gerber U (2003) Metabotropic glutamate receptors in vertebrate retina. Doc Ophthalmol 106:83-87.

Glenner GG and Wong CW (1984) Alzheimer's disease: initial report of the purification and characterization of a novel cerebrovascular amyloid protein. Biochem Biophys Res Commun 120:885-890.

Gralle M, Botelho MG, and Wouters FS (2009) Neuroprotective secreted amyloid precursor protein acts by disrupting amyloid precursor protein dimers. $J$ Biol Chem 284:15016-15025.

Gregory KJ, Noetzel MJ, and Niswender CM (2013) Pharmacology of metabotropic glutamate receptor allosteric modulators: structural basis and therapeutic potential for CNS disorders. Prog Mol Biol Transl Sci 115:61-121.

Gupta R, Nguyen DC, Schaid MD, Lei X, Balamurugan AN, Wong GW, Kim JA, Koltes JE, Kimple ME, and Bhatnagar S (2018) Complement 1q-like-3 protein inhibits insulin secretion from pancreatic $\beta$-cells via the cell adhesion $\mathrm{G}$ proteincoupled receptor BAI3. J Biol Chem 293:18086-18098.

Hamann J, Vogel B, van Schijndel GM, and van Lier RA (1996) The seven-span transmembrane receptor CD97 has a cellular ligand (CD55, DAF). J Exp Med 184 1185-1189.

Hamoud N, Tran V, Croteau LP, Kania A, and Côté JF (2014) G-protein coupled receptor BAI3 promotes myoblast fusion in vertebrates. Proc Natl Acad Sci USA 111:3745-3750

Hannan S, Wilkins ME, and Smart TG (2012) Sushi domains confer distinct trafficking profiles on GABAB receptors. Proc Natl Acad Sci USA 109:12171-12176.

Hauser AS, Attwood MM, Rask-Andersen M, Schiöth HB, and Gloriam DE (2017) Trends in GPCR drug discovery: new agents, targets and indications. Nat Rev Drug Discov 16:829-842

Hauser AS, Chavali S, Masuho I, Jahn LJ, Martemyanov KA, Gloriam DE, and Babu MM (2018) Pharmacogenomics of GPCR drug targets. Cell 172:41-54.e19.

Hawrot E, Xiao Y, Shi QL, Norman D, Kirkitadze M, and Barlow PN (1998) Demonstration of a tandem pair of complement protein modules in $\mathrm{GABA}(\mathrm{B})$ receptor 1a. FEBS Lett 432:103-108.

Hay DL and Pioszak AA (2016) Receptor activity-modifying proteins (RAMPs): new insights and roles. Annu Rev Pharmacol Toxicol 56:469-487. 
Hay DL, Walker CS, Gingell JJ, Ladds G, Reynolds CA, and Poyner DR (2016) Receptor activity-modifying proteins; multifunctional G protein-coupled receptor accessory proteins. Biochem Soc Trans 44:568-573.

Heaney CF and Kinney JW (2016) Role of GABA(B) receptors in learning and memory and neurological disorders. Neurosci Biobehav Rev 63:1-28.

Hilger D, Masureel M, and Kobilka BK (2018) Structure and dynamics of GPCR signaling complexes. Nat Struct Mol Biol 25:4-12.

Iijima T, Miura E, Watanabe M, and Yuzaki M (2010) Distinct expression of C1q-like family mRNAs in mouse brain and biochemical characterization of their encoded proteins. Eur J Neurosci 31:1606-1615.

Ishida A, Furukawa K, Keller JN, and Mattson MP (1997) Secreted form of betaamyloid precursor protein shifts the frequency dependency for induction of LTD, and enhances LTP in hippocampal slices. Neuroreport 8:2133-2137.

Jackson VA, del Toro D, Carrasquero M, Roversi P, Harlos K, Klein R, and Seiradake E (2015) Structural basis of latrophilin-FLRT interaction. Structure 23:774-781.

Jackson VA, Mehmood S, Chavent M, Roversi P, Carrasquero M, Del Toro D, SeyitBremer G, Ranaivoson FM, Comoletti D, Sansom MS, et al. (2016) Super-complexes of adhesion GPCRs and neural guidance receptors. Nat Commun 7:11184.

Jeong SJ, Luo R, Singer K, Giera S, Kreidberg J, Kiyozumi D, Shimono C, Sekiguchi $\mathrm{K}$, and Piao X (2013) GPR56 functions together with $\alpha 3 \beta 1$ integrin in regulating cerebral cortical development. PLoS One 8:e68781.

Jones KA, Borowsky B, Tamm JA, Craig DA, Durkin MM, Dai M, Yao WJ, Johnson M, Gunwaldsen C, Huang LY, et al. (1998) GABA(B) receptors function as a heteromeric assembly of the subunits $\mathrm{GABA}(\mathrm{B}) \mathrm{R} 1$ and GABA(B)R2. Nature 396: $674-679$

Kakegawa W, Mitakidis N, Miura E, Abe M, Matsuda K, Takeo YH, Kohda K, Motohashi J, Takahashi A, Nagao S, et al. (2015) Anterograde C1ql1 signaling is required in order to determine and maintain a single-winner climbing fiber in the mouse cerebellum. Neuron 85:316-329.

Karpus ON, Veninga H, Hoek RM, Flierman D, van Buul JD, Vandenakker CC, vanBavel E, Medof ME, van Lier RA, Reedquist KA, et al. (2013) Shear stressdependent downregulation of the adhesion-G protein-coupled receptor CD97 on circulating leukocytes upon contact with its ligand CD55. J Immunol 190: 3740-3748.

Kaupmann K, Malitschek B, Schuler V, Heid J, Froestl W, Beck P, Mosbacher J, Bischoff S, Kulik A, Shigemoto R, et al. (1998) GABA(B)-receptor subtypes assemble into functional heteromeric complexes. Nature 396:683-687.

Kaur B, Cork SM, Sandberg EM, Devi NS, Zhang Z, Klenotic PA, Febbraio M, Shim H, Mao H, Tucker-Burden C, et al. (2009) Vasculostatin inhibits intracranial glioma growth and negatively regulates in vivo angiogenesis through a CD36dependent mechanism. Cancer Res 69:1212-1220.

Kenzelmann D, Chiquet-Ehrismann R, and Tucker RP (2007) Teneurins, a transmembrane protein family involved in cell communication during neuronal development. Cell Mol Life Sci 64:1452-1456.

Khrimian L, Obri A, Ramos-Brossier M, Rousseaud A, Moriceau S, Nicot AS, Mera P, Kosmidis S, Karnavas T, Saudou F, et al. (2017) Gpr158 mediates osteocalcin's regulation of cognition. J Exp Med 214:2859-2873.

Kishore A and Hall RA (2016) Versatile signaling activity of adhesion GPCRs. Handb Exp Pharmacol 234:127-146.

Klein KR, Matson BC, and Caron KM (2016) The expanding repertoire of receptor activity modifying protein (RAMP) function. Crit Rev Biochem Mol Biol 51:65-71.

Knapp B and Wolfrum U (2016) Adhesion GPCR-related protein networks. Handb Exp Pharmacol 234:147-178.

Koh JT, Kook H, Kee HJ, Seo YW, Jeong BC, Lee JH, Kim MY, Yoon KC, Jung S, and Kim KK (2004) Extracellular fragment of brain-specific angiogenesis inhibitor 1 suppresses endothelial cell proliferation by blocking alphavbeta5 integrin. Exp Cell Res 294:172-184.

Krasnoperov VG, Beavis R, Chepurny OG, Little AR, Plotnikov AN, and Petrenko AG (1996) The calcium-independent receptor of alpha-latrotoxin is not a neurexin. Biochem Biophys Res Commun 227:868-875.

Küffer A, Lakkaraju AK, Mogha A, Petersen SC, Airich K, Doucerain C, Marpakwar R, Bakirci P, Senatore A, Monnard A, et al. (2016) The prion protein is an agonistic ligand of the G protein-coupled receptor Adgrg6. Nature 536:464-468.

Labbe A, Liu A, Atherton J, Gizenko N, Fortier ME, Sengupta SM, and Ridha J (2012) Refining psychiatric phenotypes for response to treatment: contribution of LPHN3 in ADHD. Am J Med Genet B Neuropsychiatr Genet 159B:776-785.

Lanoue V, Usardi A, Sigoillot SM, Talleur M, Iyer K, Mariani J, Isope P, Vodjdani G, Heintz N, and Selimi F (2013) The adhesion-GPCR BAI3, a gene linked to psychiatric disorders, regulates dendrite morphogenesis in neurons. Mol Psychiatry 18:943-950.

Lavreysen H and Dautzenberg FM (2008) Therapeutic potential of group III metabotropic glutamate receptors. Curr Med Chem 15:671-684.

Li J, Shalev-Benami M, Sando R, Jiang X, Kibrom A, Wang J, Leon K, Katanski C, Nazarko O, Lu YC, et al. (2018) Structural basis for teneurin function in circuitwiring: a toxin motif at the synapse. Cell 173:735-748.e15.

Li S, Jin Z, Koirala S, Bu L, Xu L, Hynes RO, Walsh CA, Corfas G, and Piao X (2008) GPR56 regulates pial basement membrane integrity and cortical lamination. $J$ Neurosci 28:5817-5826.

Liebscher I, Schön J, Petersen SC, Fischer L, Auerbach N, Demberg LM, Mogha A Cöster M, Simon KU, Rothemund S, et al. (2014) A tethered agonist within the ectodomain activates the adhesion G protein-coupled receptors GPR126 and GPR133. Cell Rep 9:2018-2026.

Lindenmaier LB, Parmentier N, Guo C, Tissir F, and Wright KM (2019) Dystroglycan is a scaffold for extracellular axon guidance decisions. eLife 8:e42143.

Lindsley CW, Emmitte KA, Hopkins CR, Bridges TM, Gregory KJ, Niswender CM, and Conn PJ (2016) Practical strategies and concepts in GPCR allosteric modulator discovery: recent advances with metabotropic glutamate receptors. Chem Rev 116 $6707-6741$

Little KD, Hemler ME, and Stipp CS (2004) Dynamic regulation of a GPCR-tetraspanin-G protein complex on intact cells: central role of CD81 in facilitating GPR56-Galpha q/11 association. Mol Biol Cell 15:2375-2387.
Lu YC, Nazarko OV, Sando R 3rd, Salzman GS, Li NS, Südhof TC, and Araç D (2015) Structural basis of latrophilin-FLRT-UNC5 interaction in cell adhesion. Structure 23:1678-1691.

Luo R, Jeong SJ, Jin Z, Strokes N, Li S, and Piao X (2011) G protein-coupled receptor 56 and collagen III, a receptor-ligand pair, regulates cortical development and lamination. Proc Natl Acad Sci USA 108:12925-12930.

Luo R, Jeong SJ, Yang A, Wen M, Saslowsky DE, Lencer WI, Araç D, and Piao X (2014) Mechanism for adhesion G protein-coupled receptor GPR56-mediated RhoA activation induced by collagen III stimulation. PLoS One 9:e100043.

Luo R, Jin Z, Deng Y, Strokes N, and Piao X (2012) Disease-associated mutations prevent GPR56-collagen III interaction. PLoS One 7:e29818.

Magalhaes AC, Dunn H, and Ferguson SSG (2012) Regulation of GPCR activity, trafficking and localization by GPCR-interacting proteins. $\mathrm{Br} J$ Pharmacol 165: 1717-1736.

Marshall FH, Jones KA, Kaupmann K, and Bettler B (1999) GABAB receptors - the first 7TM heterodimers. Trends Pharmacol Sci 20:396-399.

Martinelli DC, Chew KS, Rohlmann A, Lum MY, Ressl S, Hattar S, Brunger AT, Missler M, and Südhof TC (2016) Expression of C1ql3 in discrete neuronal populations controls efferent synapse numbers and diverse behaviors. Neuron 91 $1034-1051$

Martinez AF, Abe Y, Hong S, Molyneux K, Yarnell D, Löhr H, Driever W, Acosta MT, Arcos-Burgos M, and Muenke M (2016) An ultraconserved brain-specific enhancer within ADGRL3 (LPHN3) underpins attention-deficit/hyperactivity disorder susceptibility. Biol Psychiatry 80:943-954.

Meziane H, Dodart JC, Mathis C, Little S, Clemens J, Paul SM, and Ungerer A (1998) Memory-enhancing effects of secreted forms of the beta-amyloid precursor protein in normal and amnestic mice. Proc Natl Acad Sci USA 95:12683-12688.

Mogha A, Benesh AE, Patra C, Engel FB, Schöneberg T, Liebscher I, and Monk KR (2013) Gpr126 functions in Schwann cells to control differentiation and myelination via G-protein activation. J Neurosci 33:17976-17985.

Mogha A, Harty BL, Carlin D, Joseph J, Sanchez NE, Suter U, Piao X, Cavalli V, and Monk KR (2016) Gpr126/Adgrg6 has Schwann cell autonomous and nonautonomous functions in peripheral nerve injury and repair. $J$ Neurosci $\mathbf{3 6}$ 12351-12367.

Monk KR, Naylor SG, Glenn TD, Mercurio S, Perlin JR, Dominguez C, Moens CB and Talbot WS (2009) A G protein-coupled receptor is essential for Schwann cells to initiate myelination. Science 325:1402-1405.

Müller UC, Deller T, and Korte M (2017) Not just amyloid: physiological functions of the amyloid precursor protein family. Nat Rev Neurosci 18:281-298.

Nazarko O, Kibrom A, Winkler J, Leon K, Stoveken H, Salzman G, Merdas K, Lu Y, Narkhede P, Tall G, et al. (2018) A comprehensive mutagenesis screen of the adhesion GPCR latrophilin-1/ADGRL1. iScience 3:264-278.

Neuillé M, Cao Y, Caplette R, Guerrero-Given D, Thomas C, Kamasawa N, Sahel JA, Hamel CP, Audo I, Picaud S, et al. (2017) LRIT3 differentially affects connectivity and synaptic transmission of cones to ON- and OFF-bipolar cells. Invest Ophthalmol Vis Sci 58:1768-1778.

Neuillé M, El Shamieh S, Orhan E, Michiels C, Antonio A, Lancelot ME, Condroyer C, Bujakowska K, Poch O, Sahel JA, et al. (2014) Lrit3 deficient mouse (nob6): a novel model of complete congenital stationary night blindness (cCSNB). PLoS One 9:e90342.

Neuillé M, Morgans CW, Cao Y, Orhan E, Michiels C, Sahel JA, Audo I, Duvoisin RM, Martemyanov KA, and Zeitz C (2015) LRIT3 is essential to localize TRPM1 to the dendritic tips of depolarizing bipolar cells and may play a role in cone synapse formation. Eur J Neurosci 42:1966-1975.

Niciu MJ, Kelmendi B, and Sanacora G (2012) Overview of glutamatergic neurotransmission in the nervous system. Pharmacol Biochem Behav 100:656-664.

Nicoletti F, Bockaert J, Collingridge GL, Conn PJ, Ferraguti F, Schoepp DD, Wroblewski JT, and Pin JP (2011) Metabotropic glutamate receptors: from the workbench to the bedside. Neuropharmacology 60:1017-1041.

Nieberler M, Kittel RJ, Petrenko AG, Lin HH, and Langenhan T (2016) Control of adhesion GPCR function through proteolytic processing. Handb Exp Pharmacol 234:83-109.

Niswender CM and Conn PJ (2010) Metabotropic glutamate receptors: physiology, pharmacology, and disease. Annu Rev Pharmacol Toxicol 50:295-322.

Olaniru OE, Pingitore A, Giera S, Piao X, Castañera González R, Jones PM, and Persaud SJ (2018) The adhesion receptor GPR56 is activated by extracellular matrix collagen III to improve $\beta$-cell function. Cell Mol Life Sci $\mathbf{7 5}$ : 4007-4019.

Orlandi C, Omori Y, Wang Y, Cao Y, Ueno A, Roux MJ, Condomitti G, de Wit J, Kanagawa M, Furukawa T, et al. (2018) Transsynaptic binding of orphan receptor GPR179 to dystroglycan-pikachurin complex is essential for the synaptic organization of photoreceptors. Cell Rep 25:130-145.e5.

Orlandi C, Posokhova E, Masuho I, Ray TA, Hasan N, Gregg RG, and Martemyanov KA (2012) GPR158/179 regulate G protein signaling by controlling localization and activity of the RGS7 complexes. $J$ Cell Biol 197:711-719.

Orlandi C, Sutton LP, Muntean BS, Song C, and Martemyanov KA (2019) Homeostatic cAMP regulation by the RGS7 complex controls depression-related behaviors. Neuropsychopharmacology 44:642-653.

Orlandi C, Xie K, Masuho I, Fajardo-Serrano A, Lujan R, and Martemyanov KA (2015) Orphan receptor GPR158 is an allosteric modulator of RGS7 catalytic ac tivity with an essential role in dictating its expression and localization in the brain. J Biol Chem 290:13622-13639.

O'Sullivan ML, de Wit J, Savas JN, Comoletti D, Otto-Hitt S, Yates JR 3rd, and Ghosh A (2012) FLRT proteins are endogenous latrophilin ligands and regulate excitatory synapse development. Neuron 73:903-910.

O'Sullivan ML, Martini F, von Daake S, Comoletti D, and Ghosh A (2014) LPHN3, a presynaptic adhesion-GPCR implicated in $\mathrm{ADHD}$, regulates the strength of neocortical layer $2 / 3$ synaptic input to layer 5. Neural Dev 9:7.

Paavola KJ, Sidik H, Zuchero JB, Eckart M, and Talbot WS (2014) Type IV collagen is an activating ligand for the adhesion G protein-coupled receptor GPR126. Sci Signal 7:ra76. 
Padgett CL and Slesinger PA (2010) GABAB receptor coupling to G-proteins and ion channels. Adv Pharmacol 58:123-147.

Palazzo E, Marabese I, de Novellis V, Rossi F, and Maione S (2016) Metabotropic glutamate receptor 7: from synaptic function to therapeutic implications. Curr Neuropharmacol 14:504-513.

Park D, Tosello-Trampont AC, Elliott MR, Lu M, Haney LB, Ma Z, Klibanov AL, Mandell JW, and Ravichandran KS (2007) BAI1 is an engulfment receptor for apoptotic cells upstream of the ELMO/Dock180/Rac module. Nature 450:430-434.

Park SY, Yun Y, Lim JS, Kim MJ, Kim SY, Kim JE, and Kim IS (2016) Stabilin-2 modulates the efficiency of myoblast fusion during myogenic differentiation and muscle regeneration. Nat Commun 7:10871.

Pavlos NJ and Friedman PA (2017) GPCR signaling and trafficking: the long and short of it. Trends Endocrinol Metab 28:213-226.

Peachey NS, Ray TA, Florijn R, Rowe LB, Sjoerdsma T, Contreras-Alcantara S, Baba K, Tosini G, Pozdeyev N, Iuvone PM, et al. (2012) GPR179 is required for depolarizing bipolar cell function and is mutated in autosomal-recessive complete congenital stationary night blindness. Am J Hum Genet 90:331-339.

Petersen SC, Luo R, Liebscher I, Giera S, Jeong SJ, Mogha A, Ghidinelli M, Feltri ML, Schöneberg T, Piao X, et al. (2015) The adhesion GPCR GPR126 has distinct, domain-dependent functions in Schwann cell development mediated by interaction with laminin-211. Neuron 85:755-769.

Piao X, Hill RS, Bodell A, Chang BS, Basel-Vanagaite L, Straussberg R, Dobyns WB, Qasrawi B, Winter RM, Innes AM, et al. (2004) G protein-coupled receptordependent development of human frontal cortex. Science 303:2033-2036.

Pinard A, Seddik R, and Bettler B (2010) GABAB receptors: physiological functions and mechanisms of diversity. Adv Pharmacol 58:231-255

Ribasés M, Ramos-Quiroga JA, Sánchez-Mora C, Bosch R, Richarte V, Palomar G, Gastaminza X, Bielsa A, Arcos-Burgos M, Muenke M, et al. (2011) Contribution of LPHN3 to the genetic susceptibility to ADHD in adulthood: a replication study. Genes Brain Behav 10:149-157.

Rice HC, de Malmazet D, Schreurs A, Frere S, Van Molle I, Volkov AN, Creemers E, Vertkin I, Nys J, Ranaivoson FM, et al. (2019) Secreted amyloid- $\beta$ precursor protein functions as a $\mathrm{GABA}_{\mathrm{B}} \mathrm{R} 1 \mathrm{a}$ ligand to modulate synaptic transmission. Science 363:eaao4827.

Ritter SL and Hall RA (2009) Fine-tuning of GPCR activity by receptor-interacting proteins. Nat Rev Mol Cell Biol 10:819-830.

Salzman GS, Ackerman SD, Ding C, Koide A, Leon K, Luo R, Stoveken HM, Fernandez CG, Tall GG, Piao X, et al. (2016) Structural basis for regulation of GPR56/ADGRG1 by its alternatively spliced extracellular domains. Neuron 91:1292-1304.

Salzman GS, Zhang S, Gupta A, Koide A, Koide S, and Araç D (2017) Stachelindependent modulation of GPR56/ADGRG1 signaling by synthetic ligands directed to its extracellular region. Proc Natl Acad Sci USA 114:10095-10100.

Sarrazin S, Lamanna WC, and Esko JD (2011) Heparan sulfate proteoglycans. Cold Spring Harb Perspect Biol 3:a004952.

Sarria I, Cao Y, Wang Y, Ingram NT, Orlandi C, Kamasawa N, Kolesnikov AV, Pahlberg J, Kefalov VJ, Sampath AP, et al. (2018) LRIT1 modulates adaptive changes in synaptic communication of cone photoreceptors. Cell Rep 22:3562-3573.

Sarria I, Orlandi C, McCall MA, Gregg RG, and Martemyanov KA (2016) Intermolecular interaction between anchoring subunits specify subcellular targeting and function of RGS proteins in retina ON-bipolar neurons. $J$ Neurosci 36:2915-2925.

Sato S, Omori Y, Katoh K, Kondo M, Kanagawa M, Miyata K, Funabiki K, Koyasu T, Kajimura N, Miyoshi T, et al. (2008) Pikachurin, a dystroglycan ligand, is essential for photoreceptor ribbon synapse formation. Nat Neurosci 11:923-931.

Scheiffele P, Fan J, Choih J, Fetter R, and Serafini T (2000) Neuroligin expressed in nonneuronal cells triggers presynaptic development in contacting axons. Cell 101: $657-669$.

Scholz N, Guan C, Nieberler M, Grotemeyer A, Maiellaro I, Gao S, Beck S, Pawlak M, Sauer M, Asan E, et al. (2017) Mechano-dependent signaling by latrophilin/CIRL quenches cAMP in proprioceptive neurons. eLife 6:e28360.

Schwenk J, Pérez-Garci E, Schneider A, Kollewe A, Gauthier-Kemper A, Fritzius T, Raveh A, Dinamarca MC, Hanuschkin A, Bildl W, et al. (2016) Modular composition and dynamics of native GABAB receptors identified by high-resolution proteomics. Nat Neurosci 19:233-242.

Siddiqui TJ, Tari PK, Connor SA, Zhang P, Dobie FA, She K, Kawabe H, Wang YT, Brose N, and Craig AM (2013) An LRRTM4-HSPG complex mediates excitatory synapse development on dentate gyrus granule cells. Neuron 79:680-695.

Sigoillot SM, Iyer K, Binda F, González-Calvo I, Talleur M, Vodjdani G, Isope P, and Selimi F (2015) The secreted protein C1QL1 and its receptor BAI3 control the synaptic connectivity of excitatory inputs converging on cerebellar Purkinje cells. Cell Rep 10:820-832.

Silva JP, Lelianova VG, Ermolyuk YS, Vysokov N, Hitchen PG, Berninghausen O, Rahman MA, Zangrandi A, Fidalgo S, Tonevitsky AG, et al. (2011) Latrophilin 1 and its endogenous ligand Lasso/teneurin-2 form a high-affinity transsynaptic receptor pair with signaling capabilities. Proc Natl Acad Sci USA 108: $12113-12118$

Sriram K and Insel PA (2018) G protein-coupled receptors as targets for approved drugs: how many targets and how many drugs? Mol Pharmacol 93:251-258.

Stachniak TJ, Sylwestrak EL, Scheiffele P, Hall BJ, and Ghosh A (2019) Elfn1-induced constitutive activation of mGluR7 determines frequency-dependent recruitment of somatostatin interneurons. J Neurosci 39:4461-4474.

Stehlik C, Kroismayr R, Dorfleutner A, Binder BR, and Lipp J (2004) VIGR--a novel inducible adhesion family G-protein coupled receptor in endothelial cells. FEBS Lett 569:149-155.

Stephenson JR, Paavola KJ, Schaefer SA, Kaur B, Van Meir EG, and Hall RA (2013) Brain-specific angiogenesis inhibitor-1 signaling, regulation, and enrichment in the postsynaptic density. J Biol Chem 288:22248-22256.

Stoeckli ET (2010) Neural circuit formation in the cerebellum is controlled by cell adhesion molecules of the Contactin family. Cell Adhes Migr 4:523-526.
Stoveken HM, Hajduczok AG, Xu L, and Tall GG (2015) Adhesion G protein-coupled receptors are activated by exposure of a cryptic tethered agonist. Proc Natl Acad Sci USA 112:6194-6199.

Sutton LP, Orlandi C, Song C, Oh WC, Muntean BS, Xie K, Filippini A, Xie X, Satterfield R, Yaeger JDW, et al. (2018) Orphan receptor GPR158 controls stressinduced depression. eLife 7:e33273.

Sylwestrak EL and Ghosh A (2012) Elfn1 regulates target-specific release probability at CA1-interneuron synapses. Science 338:536-540.

Tan A, Ke S, Chen Y, Chen L, Lu X, Ding F, Yang L, Tang Y, and Yu Y (2019) Expression patterns of C1q14 and its cell-adhesion GPCR Bai3 in the murine testis and functional roles in steroidogenesis. FASEB J 33:4893-4906.

Taniguchi H, Gollan L, Scholl FG, Mahadomrongkul V, Dobler E, Limthong N, Peck M, Aoki C, and Scheiffele P (2007) Silencing of neuroligin function by postsynaptic neurexins. J Neurosci 27:2815-2824.

Taylor CJ, Ireland DR, Ballagh I, Bourne K, Marechal NM, Turner PR, Bilkey DK, Tate WP, and Abraham WC (2008) Endogenous secreted amyloid precursor protein-alpha regulates hippocampal NMDA receptor function, long-term potentiation and spatial memory. Neurobiol Dis 31:250-260.

Thompson MD, Burnham WM, and Cole DE (2005) The G protein-coupled receptors: pharmacogenetics and disease. Crit Rev Clin Lab Sci 42:311-392.

Thompson MD, Siminovitch KA, and Cole DE (2008) G protein-coupled receptor pharmacogenetics. Methods Mol Biol 448:139-185.

Tiao JY, Bradaia A, Biermann B, Kaupmann K, Metz M, Haller C, Rolink AG, Pless E, Barlow PN, Gassmann M, et al. (2008) The sushi domains of secreted GABA(B1) isoforms selectively impair GABA(B) heteroreceptor function. $J$ Biol Chem 283 : 31005-31011.

Tomioka NH, Yasuda H, Miyamoto H, Hatayama M, Morimura N, Matsumoto Y, Suzuki T, Odagawa M, Odaka YS, Iwayama Y, et al. (2014) Elfn1 recruits presynaptic mGluR7 in trans and its loss results in seizures. Nat Commun 5:4501.

Tu YK, Duman JG, and Tolias KF (2018) The adhesion-GPCR BAI1 promotes excitatory synaptogenesis by coordinating bidirectional trans-synaptic signaling. $J$ Neurosci 38:8388-8406.

Ueno A, Omori Y, Sugita Y, Watanabe S, Chaya T, Kozuka T, Kon T, Yoshida S, Matsushita K, Kuwahara R, et al. (2018) Lrit1, a retinal transmembrane protein, regulates selective synapse formation in cone photoreceptor cells and visual acuity. Cell Rep 22:3548-3561.

Um JW, Kaufman AC, Kostylev M, Heiss JK, Stagi M, Takahashi H, Kerrisk ME, Vortmeyer A, Wisniewski T, Koleske AJ, et al. (2013) Metabotropic glutamate receptor 5 is a coreceptor for Alzheimer a $\beta$ oligomer bound to cellular prion protein. Neuron 79:887-902.

Ushkaryov YA, Hata Y, Ichtchenko K, Moomaw C, Afendis S, Slaughter CA and Südhof TC (1994) Conserved domain structure of beta-neurexins. Unusual cleaved signal sequences in receptor-like neuronal cell-surface proteins. $J$ Biol Chem 269:11987-11992.

Vassilatis DK, Hohmann JG, Zeng H, Li F, Ranchalis JE, Mortrud MT, Brown A, Rodriguez SS, Weller JR, Wright AC, et al. (2003) The G protein-coupled receptor repertoires of human and mouse. Proc Natl Acad Sci USA 100:4903-4908.

Vigot R, Barbieri S, Bräuner-Osborne H, Turecek R, Shigemoto R, Zhang YP, Luján R, Jacobson LH, Biermann B, Fritschy JM, et al. (2006) Differential compartmentalization and distinct functions of GABAB receptor variants. Neuron 50:589-601.

Vysokov NV, Silva JP, Lelianova VG, Ho C, Djamgoz MB, Tonevitsky AG, and Ushkaryov YA (2016) The mechanism of regulated release of Lasso/teneurin-2. Front Mol Neurosci 9:59.

Vysokov NV, Silva JP, Lelianova VG, Suckling J, Cassidy J, Blackburn JK, Yankova N, Djamgoz MB, Kozlov SV, Tonevitsky AG, et al. (2018) Proteolytically released Lasso/teneurin-2 induces axonal attraction by interacting with latrophilin-1 on axonal growth cones. eLife 7:e37935.

Wandel E, Saalbach A, Sittig D, Gebhardt C, and Aust G (2012) Thy-1 (CD90) is an interacting partner for CD97 on activated endothelial cells. $J$ Immunol 188: $1442-1450$

Wang T, Ward Y, Tian L, Lake R, Guedez L, Stetler-Stevenson WG, and Kelly K (2005) CD97, an adhesion receptor on inflammatory cells, stimulates angiogenesis through binding integrin counterreceptors on endothelial cells. Blood 105:2836-2844.

Westergard L, Christensen HM, and Harris DA (2007) The cellular prion protein $(\operatorname{PrP}(\mathrm{C}))$ : its physiological function and role in disease. Biochim Biophys Acta 1772: $629-644$.

White JH, Wise A, Main MJ, Green A, Fraser NJ, Disney GH, Barnes AA, Emson P, Foord SM, and Marshall FH (1998) Heterodimerization is required for the formation of a functional GABA(B) receptor. Nature 396:679-682.

Wu MP, Doyle JR, Barry B, Beauvais A, Rozkalne A, Piao X, Lawlor MW, Kopin AS Walsh CA, and Gussoni E (2013) G-protein coupled receptor 56 promotes myoblast fusion through serum response factor- and nuclear factor of activated T-cell-mediated signalling but is not essential for muscle development in vivo. FEBS $J \mathbf{2 8 0}$ : $6097-6113$

Xiong M, Jones OD, Peppercorn K, Ohline SM, Tate WP, and Abraham WC (2017) Secreted amyloid precursor protein-alpha can restore novel object location memory and hippocampal LTP in aged rats. Neurobiol Learn Mem 138:291-299.

Xu L, Begum S, Hearn JD, and Hynes RO (2006) GPR56, an atypical G protein-coupled receptor, binds tissue transglutaminase, TG2, and inhibits melanoma tumor growth and metastasis. Proc Natl Acad Sci USA 103:9023-9028.

Young TR and Leamey CA (2009) Teneurins: important regulators of neural circuitry. Int $J$ Biochem Cell Biol 41:990-993.

Yuzaki M (2010) Synapse formation and maintenance by C1q family proteins: a new class of secreted synapse organizers. Eur J Neurosci 32:191-197.

Zuko A, Oguro-Ando A, Post H, Taggenbrock RL, van Dijk RE, Altelaar AF, Heck AJ, Petrenko AG, van der Zwaag B, Shimoda Y, et al. (2016) Association of cell adhesion molecules contactin-6 and latrophilin-1 regulates neuronal apoptosis. Front Mol Neurosci 9:143. 